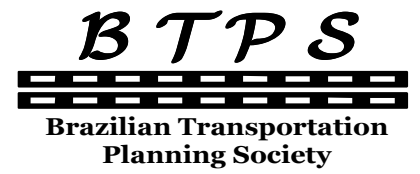

Planning Society

\author{
Journal of Transport Literature \\ Vol. 8, n. 3, pp. 139-171, Jul. 2014 \\ Research Directory
}

JTL|RELIT

www.transport-literature.org ISSN 2238-1031

\title{
Análise da evolução das taxas de geração de viagens publicadas pelo ITE para estabelecimentos de ensino
}

[Analysis of the evolution of trip generation rates associated to education institutions as published by ITE]

\author{
Ângela Beatriz Souza Bertazzo*, Maria Alice Prudêncio Jacques, \\ Jorge Galarraga, Marcelo Herz \\ Brasília Federal Education Institute - Brazil, University of Brasília - Brazil, \\ Córdoba National University - Argentina, Córdoba National University - Argentina
}

Submitted 6 May 2013; received in revised form 30 Sep 2013; accepted 1 Nov 2013

\begin{abstract}
Resumo
O presente artigo faz uma análise da documentação incluída em diferentes edições do manual Trip Generation, publicado pelo ITE (Institute of Transportation Engineers), para os usos do solo 530 (Instituições de Ensino Médio) e 550 (Universidades), contemplando um período de avaliação superior a 20 anos. São feitas considerações e recomendações sobre a possibilidade de aplicação das taxas propostas na Edição 2012 do manual do ITE para estimar o número de viagens de automóvel geradas por instituições de ensino médio e universidades localizadas no Brasil. Em geral, o estudo mostrou que o uso dessas taxas superestima o número de viagens observadas nas instituições nacionais. Além disso, foi verificado que as taxas e modelos de geração de viagens de cada edição do manual do ITE são obtidos a partir da agregação de novos estudos à base de dados da edição anterior, sem que estudos mais antigos sejam descartados. Isso é, os esforços mais recentes para alterar a distribuição modal das viagens geradas pelos polos geradores de viagens não são plenamente capturados nas novas edições.
\end{abstract}

Palavras-Chave: polos geradores de viagens, taxas de geração de viagens, intituição de ensino médio, universidade, manual do ITE.

\begin{abstract}
This paper reviews and analyzes the land use documentation included in various editions of the Trip Generation manual published by the Institute of Transportation Engineers (ITE) concerning Land Use: 530 (High School) and Land Use: 550 (University) and spanning an assessment period of more than 20 years. Remarks and recommendations are made on the possibility of using the rates proposed in the 2012 edition of the manual to estimate the number of automobile trips generated by high schools and universities in Brazil. Overall the study showed that such rates lead to overestimates of trips as compared to those actually observed in Brazilian institutions. Furthermore, it was found that the rates and models adopted in each successive edition of the ITE manual are obtained by aggregating the more recent studies to the database of the preceding edition without discarding the older studies so that more recent efforts to alter the modal distribution for trips generated by such sites are not fully captured in the newest editions.

Key words: trip generators, trip generation rates, high school, university, ITE manual (2012 edition).

*Email: angela.bertazzo@hotmail.com.
\end{abstract}

\section{Recommended Citation}

Bertazzo, A. B. S., Jacques, M. A. P., Galarraga, J. and Herz, M. (2014) Análise da evolução das taxas de geração de viagens publicadas pelo ITE para estabelecimentos de ensino. Journal of Transport Literature, vol. 8, n. 3, pp. 139-171.

- JTL/RELIT is a fully electronic, peer-reviewed, open access, international journal focused on emerging transport markets and published by BPTS - Brazilian Transport Planning Society. Website www.transport-literature.org. ISSN 2238-1031. 


\section{Introdução}

A estimativa do número de viagens por motivos de estudo, a distribuição modal e a concentração dessas viagens ao longo do tempo são temas relevantes para o planejamento do uso do solo e para a avaliação do impacto da implantação de estabelecimentos de ensino enquanto polos geradores de viagens.

O ITE (Institute of Transportation Engineers) publica desde 1976, com a primeira edição do documento Trip Generation, taxas de geração de viagens e, em alguns casos, modelos de regressão a elas associados, referentes a diversos tipos de usos do solo. Essas taxas são determinadas com base em estudos realizados nos Estados Unidos desde o final dos anos sessenta (ITE, 1991). A cada nova edição do Trip Generation, que teve sua $9^{a}$ Edição publicada em 2012 (ITE, 2012), novos estudos e novos tipos de solo são agregados. Isto é, para a determinação de novas taxas e modelos, o ITE trabalha com uma base de dados cada vez mais ampla. Se por um lado isso representa uma vantagem, no sentido da obtenção de parâmetros mais significativos, por outro lado pode representar uma desvantagem para as análises de empreendimentos atuais. Essa desvantagem decorre do fato de que as taxas misturam, para um mesmo tipo de uso do solo, condições diferenciadas de ocupação do sistema viário, de escolha modal por parte dos usuários dos polos geradores, de controle e gerenciamento do tráfego, dentre outras, que naturalmente sofrem alterações ao longo do tempo, especialmente de décadas.

Outro aspecto que precisa ser considerado com relação ao uso das taxas de geração de viagem para a previsão do impacto causado por novos empreendimentos, decorrentes das viagens por eles geradas, é que essas taxas usualmente refletem um tipo de padrão de escolha modal fortemente vinculado ao uso dos veículos privados. Conforme discutido em Shoup (2001) e Jacques et al. (2010), a reprodução dessa situação em novos empreendimentos deveria ser, no mínimo, questionada com base nas premissas mais atuais de estímulo ao uso de modos de transporte alternativos ao automóvel (motorizados e não-motorizados). 
Neste contexto, o objetivo do presente artigo é fazer uma análise da evolução temporal das taxas de geração de viagens publicadas pelo ITE nas suas últimas três edições $\left(7^{\mathrm{a}}, 8^{\mathrm{a}}\right.$ e $9^{\mathrm{a}}$ edições), confrontando-as com uma edição mais antiga, a 5a edição, publicada em 1991. Essa análise, que contempla um período de tempo de mais de duas décadas, permitirá que se avalie como a estratégia do ITE de complementar continuamente sua base de dados se reflete nos valores obtidos para as taxas de geração e parâmetros dos modelos de geração presentes nas diferentes edições. $O$ foco do artigo é nas instituições de ensino, especificamente nas Universidades (Uso do Solo 550 do ITE) e nas Instituições de Ensino Médio (Uso do Solo 530 do ITE).

O presente documento está estruturado em cinco seções, a primeira sendo essa seção introdutória. Na Seção 1 é feita uma avaliação do número de estudos envolvidos nas edições consideradas, juntamente com a caracterização das escolas em termos do número de alunos, de empregados e de área construída. São incluídos também os dados adicionais apresentados pelo ITE nas edições analisadas. A análise da evolução das taxas e modelos é apresentada na Seção 2, e na Seção 3 é verificada a aplicabilidade das taxas e modelos da última edição do Trip Generation (ITE, 2012) a instituições de ensino localizadas no Brasil. Na última seção são apresentadas as conclusões do estudo.

\section{Características gerais dos estudos}

Conforme referido anteriormente, o presente artigo considera as seguintes edições do Trip Generation: $5^{\text {a }}$ Edição (ITE, 1991); $7^{\text {a }}$ Edição (ITE, 2003); $8^{\text {a }}$ Edição (ITE, 2008); e $9^{\text {a }}$ Edição (ITE, 2012). Nesta seção é analisada, para as Universidades e para as Instituições de Ensino Médio (IEMs), a evolução de alguns aspectos metodológicos envolvidos na determinação das taxas e dos modelos de geração de viagens. O porte das instituições envolvidas, representado pelo número de alunos e empregados e área construída também é avaliado. 


\subsection{Instituições de Ensino Médio (IEMs) - Uso do Solo 530 do ITE}

$\mathrm{Na}$ apresentação das taxas e modelos referentes a esse tipo de uso do solo, o ITE inclui alguns dados adicionais, importantes para o adequado uso do material, que são idênticos para as três últimas edições, mas que diferem em alguma medida dos apresentados na edição de 1991. A Tabela 1 permite a visualização dessas semelhanças e diferenças.Por meio da Tabela 1 verifica-se a preocupação do ITE em destacar a necessidade da realização de estudos que definam a percentagem de estudantes que usa o ônibus escolar e o transporte público desde, pelo menos, 1991. No entanto, aparentemente, os pesquisadores americanos ainda não conseguiram obter resultados para serem incluídos nas versões mais recentes do Trip Generation. A questão de que o número de estudantes é, potencialmente, uma variável explicativa mais adequada para a previsão do número de viagens geradas por IEMs também é abordada desde 2003, juntamente com o destaque dado à importância dos estudos indicarem claramente se a escola pesquisada é pública ou privada. O reconhecimento a respeito da grande diferença socioeconômica das populações atendidas pelas escolas não resulta numa indicação explicita de que essa diferença deve ser incluída em futuros estudos. No entanto, esse é um aspecto a ser levado em conta por pesquisadores de países em desenvolvimento, onde essas diferenças tendem a ser ainda mais acentuadas.

Na Tabela 2 é apresentado um resumo da quantidade de estudos considerados para a definição das taxas e modelos (quando existirem) para as três variáveis independentes consideradas pelo ITE nas diferentes edições do Trip Generation, que são: número de estudantes; número de empregados; e número de 1000 pés $^{2}$ de área bruta construída. Dentre os períodos de referência disponibilizados pelo ITE optou-se por abordar somente os dias úteis, dada sua importância para a geração das viagens por motivo escola. 
Tabela 1 - Dados adicionais apresentados para as

\section{Instituições de Ensino Médio nas edições analisadas}

\begin{tabular}{|c|c|c|}
\hline Tópico & ITE, 1991 & ITE, 2003; ITE, 2008; ITE, 2012 \\
\hline \multirow{2}{*}{$\begin{array}{l}\text { Número médio de viagens em } \\
\text { dias úteis por transporte público }\end{array}$} & $\begin{array}{l}\text { 57\% dos estudantes das escolas } \\
\text { pesquisadas são transportados } \\
\text { por ornibus escolar ou } \\
\text { transporte público. }\end{array}$ & $\begin{array}{l}\text { A percentagem de estudantes que } \\
\text { usam ônibus escolar ou transporte } \\
\text { público varia consideravelmente } \\
\text { entre as escolas pesquisadas. }\end{array}$ \\
\hline & $\begin{array}{l}\text { É desejável que futuros estudos } \\
\text { sejam realizados sobre esse } \\
\text { tipo de viagem. }\end{array}$ & $\begin{array}{l}\text { É desejável que futuros estudos } \\
\text { sejam realizados sobre esse tipo } \\
\text { de viagem. }\end{array}$ \\
\hline Viagens realizadas por pessoas & Informação não disponível & $\begin{array}{l}\text { Informação não disponível, nem } \\
\text { referenciada }\end{array}$ \\
\hline Viagens de caminhões & Informação não disponível & $\begin{array}{l}\text { Informação não disponível, nem } \\
\text { referenciada. }\end{array}$ \\
\hline Ocupação dos veículos & Informação não disponível & $\begin{array}{l}\text { Informação não disponível, nem } \\
\text { referenciada. }\end{array}$ \\
\hline Horas pico do gerador & $\begin{array}{l}\text { Em dias úteis coincide com a } \\
\text { hora de pico da manhã da via } \\
\text { adjacente. A hora-pico da tarde } \\
\text { do gerador em dias úteis ocorre } \\
\text { no período das } 14 \mathrm{~h} \text { às } 15 \mathrm{~h} \text {. }\end{array}$ & $\begin{array}{l}\text { Em dias úteis coincide com a hora } \\
\text { de pico da manhã da via } \\
\text { adjacente. Por essa razão, somente } \\
\text { os dados referentes ao pico da } \\
\text { manhã do gerador são } \\
\text { apresentados. A hora-pico da tarde } \\
\text { do gerador em dias úteis ocorre no } \\
\text { período das } 14 \mathrm{~h} \text { às } 16 \mathrm{~h} \text {. }\end{array}$ \\
\hline Realização dos estudos & $\begin{array}{l}\text { Os estudos foram realizados no } \\
\text { período entre o final dos anos } \\
1960 \text { e os anos 1980, em locais } \\
\text { distribuídos ao longo dos } \\
\text { Estados Unidos. }\end{array}$ & $\begin{array}{l}\text { Os estudos foram realizados no } \\
\text { período entre o final dos anos } \\
1960 \text { e os anos } 2000 \text {, em locais } \\
\text { distribuídos ao longo dos Estados } \\
\text { Unidos. }\end{array}$ \\
\hline $\begin{array}{l}\text { Facilidades oferecidas pelas } \\
\text { escolas }\end{array}$ & $\begin{array}{l}\text { As escolas pesquisadas variam } \\
\text { consideravelmente em termos } \\
\text { das infraestruturas oferecidas: } \\
\text { área construída de } 54 \text { a } 410 \\
\text { pés }{ }^{2} / \text { estudante } \\
\text { (aproximadamente } 5 \text { a } 38 \mathrm{~m}^{2} \\
\text { por estudante) } 0,41 \text { a } 0,90 \\
\text { vagas de estacionamento por } \\
\text { estudante; } 1,4 \text { a } 5,5 \text { estudantes } \\
\text { por empregado. }\end{array}$ & $\begin{array}{l}\text { As escolas pesquisadas variam } \\
\text { consideravelmente em termos das } \\
\text { facilidades oferecidas. Como a } \\
\text { área construída por aluno varia } \\
\text { muito entre as escolas } \\
\text { pesquisadas, o número de } \\
\text { estudantes pode ser uma variável } \\
\text { independente mais confiável na } \\
\text { definição das taxas de geração de } \\
\text { viagens. }\end{array}$ \\
\hline $\begin{array}{l}\text { Número de viagens nos finais de } \\
\text { semana }\end{array}$ & $\begin{array}{l}\text { Informação não disponível, } \\
\text { nem referenciada }\end{array}$ & $\begin{array}{l}\text { A geração de viagens nos períodos } \\
\text { em finais de semana varia } \\
\text { consideravelmente e, por isso, as } \\
\text { estatísticas referentes a esses } \\
\text { períodos devem ser utilizadas com } \\
\text { cautela. }\end{array}$ \\
\hline $\begin{array}{l}\text { Características das populações } \\
\text { atendidas }\end{array}$ & $\begin{array}{l}\text { Informação não disponível, } \\
\text { nem referenciada }\end{array}$ & $\begin{array}{l}\text { As populações atendidas pelas } \\
\text { escolas possuem características } \\
\text { socioeconômicas muito diferentes } \\
\text { entre si. }\end{array}$ \\
\hline Características das escolas & $\begin{array}{l}\text { Informação não disponível, } \\
\text { nem referenciada. }\end{array}$ & $\begin{array}{l}\text { Algumas das escolas pesquisadas } \\
\text { são públicas e outras são privadas. } \\
\text { Estudos futuros devem levar em } \\
\text { conta o tipo da escola. }\end{array}$ \\
\hline
\end{tabular}


Tabela 2 - Quantidade de estudos realizados para Instituições de Ensino Médio

\begin{tabular}{|c|c|c|c|c|c|}
\hline $\begin{array}{c}\text { Variável } \\
\text { Independente }(\mathrm{X})\end{array}$ & Período de tempo & ITE, 1991 & ITE, 2003 & ITE, 2008 & ITE, 2012 \\
\hline \multirow{5}{*}{ Estudantes } & Dia útil & 27 & 51 & 51 & 51 \\
\hline & $(1)$ & 3 & nd & nd & nd \\
\hline & (2) & 3 & 34 & 40 & 40 \\
\hline & (3) & 28 & 62 & 68 & 75 \\
\hline & (4) & 30 & 62 & 68 & 74 \\
\hline \multirow{5}{*}{ Empregados } & Dia útil & 27 & 51 & 51 & 51 \\
\hline & (1) & 1 & nd & nd & nd \\
\hline & (2) & 1 & 24 & 25 & 25 \\
\hline & (3) & 27 & 52 & 53 & 53 \\
\hline & $(4)$ & 27 & 52 & 53 & 53 \\
\hline \multirow{5}{*}{$\begin{array}{c}1000 \text { pés }^{2} \\
\text { (aproximadamente } \\
92,90 \mathrm{~m}^{2} \text { ) de área } \\
\text { bruta construída } \\
(\mathrm{GFA})\end{array}$} & Dia útil & 20 & 43 & 43 & 43 \\
\hline & $(1)$ & 1 & nd & nd & nd \\
\hline & (2) & 1 & 22 & 22 & 22 \\
\hline & (3) & 20 & 44 & 44 & 44 \\
\hline & (4) & 20 & 44 & 44 & 44 \\
\hline
\end{tabular}

Legenda:

(1) Dia útil, hora-pico da manhã do tráfego da via adjacente

(2) Dia útil, hora-pico da tarde do tráfego da via adjacente

(3) Dia útil, hora-pico da manhã do gerador

(4) Dia útil, hora-pico da tarde do gerador

nd $=$ não disponível

1 pé quadrado $=0,092903 \mathrm{~m}^{2}$

A partir da Tabela 2 é possível observar que entre 1991 e 2003 (12 anos) houve um aumento substancial do número de estudos referentes à IEMs como polos geradores de viagens. Para a variável "número de estudantes" e os períodos correspondentes à hora-pico da manhã e da tarde do gerador, por exemplo, o número de estudos praticamente dobrou. Situação diferente pode ser observada nos nove anos seguintes (entre 2003 e 2012), onde o número de escolas estudadas para os mesmos períodos cresceu somente em torno de $20 \%$. Já entre as duas últimas versões, somente 7 novos estudos foram agregados para o período da hora-pico da manhã do gerador e 6 para a hora-pico da tarde, representando um aumento de aproximadamente $10 \%$ no número total de estudos. Esta pode ser uma das razões pelas quais nas edições mais recentes o ITE continua a considerar dados coletados no final da década de 1960.

Para que se possa avaliar o porte das instituições inseridas no estudo, a Tabela 3 apresenta alguns dados que permitem essa avaliação, especificamente para os períodos de hora-pico da manhã e da tarde do gerador, em dias úteis. Os dados revelam que os estudos incluídos após a edição de 1991 contemplaram escolas com porte semelhantes, apresentando número de alunos 
no intervalo de 150 a 2950, número de empregados entre 40 e 230 e área bruta construída variando de 50.000 a 360.000 pés $^{2}$ (entre $4.645 \mathrm{~m}^{2}$ e $33.445 \mathrm{~m}^{2}$ ).

Tabela 3 - Dados gerais das IEMs estudadas

\begin{tabular}{|c|c|c|c|c|c|}
\hline \multirow{2}{*}{$\begin{array}{c}\text { Variável } \\
\text { Independente }(\mathrm{X})\end{array}$} & \multirow{2}{*}{$\begin{array}{l}\text { Período de } \\
\text { tempo }\end{array}$} & \multirow{2}{*}{$\begin{array}{l}\text { Edição ITE } \\
\text { (Ano) }\end{array}$} & \multicolumn{3}{|c|}{ Valor da variável independente (X) } \\
\hline & & & Média & $\operatorname{Mínimo(*)}$ & Máximo(*) \\
\hline \multirow{8}{*}{ Estudantes } & \multirow{4}{*}{$\begin{array}{l}\text { Dia útil, hora- } \\
\text { pico da manhã } \\
\text { do gerador }\end{array}$} & 1991 & 1222 & 150 & 2900 \\
\hline & & 2003 & 1290 & 200 & 2950 \\
\hline & & 2008 & 1292 & 200 & 2950 \\
\hline & & 2012 & 1231 & 200 & 2950 \\
\hline & \multirow{4}{*}{$\begin{array}{l}\text { Dia útil, hora- } \\
\text { pico da tarde } \\
\text { do gerador }\end{array}$} & 1991 & 1296 & 150 & 2900 \\
\hline & & 2003 & 1290 & 200 & 2950 \\
\hline & & 2008 & 1292 & 200 & 2950 \\
\hline & & 2012 & 1235 & 200 & 2950 \\
\hline \multirow{8}{*}{ Empregados } & \multirow{4}{*}{$\begin{array}{l}\text { Dia útil, hora- } \\
\text { pico da manhã } \\
\text { do gerador }\end{array}$} & 1991 & 103 & 42 & 225 \\
\hline & & 2003 & 119 & 41 & 225 \\
\hline & & 2008 & 118 & 41 & 225 \\
\hline & & 2012 & 118 & 42 & 225 \\
\hline & \multirow{4}{*}{$\begin{array}{l}\text { Dia útil, hora- } \\
\text { pico da tarde } \\
\text { do gerador }\end{array}$} & 1991 & 103 & 42 & 225 \\
\hline & & 2003 & 119 & 41 & 225 \\
\hline & & 2008 & 118 & 41 & 225 \\
\hline & & 2012 & 118 & 45 & 225 \\
\hline \multirow{8}{*}{$\begin{array}{c}1000 \text { pés }^{2} \\
\text { (aproximadamente } \\
92,90 \mathrm{~m}^{2} \text { ) de área } \\
\text { bruta construída } \\
\text { (GFA) }\end{array}$} & \multirow{4}{*}{$\begin{array}{l}\text { Dia útil, hora- } \\
\text { pico da manhã } \\
\text { do gerador }\end{array}$} & 1991 & 164 & 50 & 330 \\
\hline & & 2003 & 194 & 55 & 360 \\
\hline & & 2008 & 194 & 55 & 360 \\
\hline & & 2012 & 194 & 55 & 360 \\
\hline & \multirow{4}{*}{$\begin{array}{l}\text { Dia útil, hora- } \\
\text { pico da tarde } \\
\text { do gerador }\end{array}$} & 1991 & 164 & 50 & 330 \\
\hline & & 2003 & 194 & 55 & 360 \\
\hline & & 2008 & 194 & 55 & 360 \\
\hline & & 2012 & 194 & 55 & 360 \\
\hline
\end{tabular}

Legenda: (*) Valor estimado a partir dos gráficos apresentados no manual Trip Generation 1 pé quadrado $=0,092903 \mathrm{~m}^{2}$

\subsection{Universidades - Uso do Solo 550 do ITE}

$\mathrm{Na}$ apresentação das taxas e modelos referentes a esse tipo de uso do solo, o ITE inclui alguns dados adicionais, importantes para o adequado uso do material, que são muito semelhantes para as Edições 2003 e 2008, mas que diferem em alguma medida dos apresentados nas Edições 1991 e 2012. A Tabela 4 permite a visualização dessas semelhanças e diferenças.

Na Edição 2012 fica clara a preocupação do ITE com o impacto da disponibilidade do transporte público sobre as taxas de geração de viagens. Em todas as edições do ITE 
analisadas neste artigo, o número de estudantes é recomendado como a variável independente mais adequada.

No que se refere às variáveis independentes e períodos de tempo de análise, as edições do

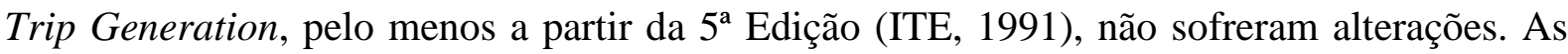
variáveis independentes consideradas são o número de estudantes e o número de empregados. Pela primeira vez, em sua $9^{a}$ Edição (ITE, 2012), o Trip Generation oferece uma definição para "estudante", segundo a qual este é uma pessoa que está matriculada na instituição, seja em tempo integral ou parcial.

O número de estudantes se refere, portanto, aos estudantes matriculados e não aos presentes na instituição no momento da realização do estudo. Um "empregado", por sua vez, é definido como um trabalhador em tempo integral ou parcial. O número de empregados se refere à quantidade de pessoas que trabalham na instituição, independentemente dos que estavam presentes no momento da realização do estudo.

Com relação aos períodos de tempo, para as duas variáveis independentes, o ITE especifica: (a) dia útil; (b) hora-pico na via adjacente no período da manhã; (c) hora-pico na via adjacente no período da tarde; (d) hora-pico do gerador no período da manhã; (e) hora-pico do gerador no período da tarde; e (f) sábado.

No que se refere à base de dados, observa-se que a mesma foi sendo ampliada ao longo do tempo. A Tabela 5 mostra a informação correspondente à quantidade de estudos para cada variável e período de tempo. Os dados da Tabela 5 revelam que, embora tenha havido um aumento no número de estudos, a quantidade em 2012 ainda é relativamente baixa. Para o dia de sábado, por exemplo, se conta somente com dois estudos e os mesmos são anteriores ao ano de 1991. Para a variável independente "empregados”, as Edições 1991, 2003 e 2008 não apresentam variação na quantidade de estudos, enquanto a Edição 2012 incorpora dois novos estabelecimentos de ensino. Já no que diz respeito à variável independente "número de estudantes", a Edição 2003 apresenta dois estudos a mais do que a Edição de 1991, ambos relacionados à hora-pico da manhã e da tarde, em dias úteis, para a via adjacente. Finalmente, a Edição 2012 incorpora dois novos estudos referentes a todos os períodos de tempo (exceto sábado). Esses dois estudos tratam de estabelecimentos com maior número de estudantes e empregados, estando situados em área atendida por serviços de transporte público. 
Tabela 4 - Dados adicionais apresentados para Universidades nas edições analisadas

\begin{tabular}{|c|c|c|c|}
\hline Tópico & ITE, 1991 & $\begin{array}{c}\text { ITE, 2003; ITE, } \\
2008\end{array}$ & ITE, 2012 \\
\hline $\begin{array}{l}\text { Impacto da } \\
\text { disponibilidade } \\
\text { de transporte } \\
\text { público }\end{array}$ & Informação não disponível & $\begin{array}{l}\text { Informação não } \\
\text { disponível, nem } \\
\text { referenciada }\end{array}$ & $\begin{array}{l}\text { Dois estudos indicaram } \\
\text { que a área dispunha de } \\
\text { transporte público. As } \\
\text { taxas de geração obtidas } \\
\text { foram menores. }\end{array}$ \\
\hline $\begin{array}{l}\text { Viagens } \\
\text { realizadas por } \\
\text { pessoas }\end{array}$ & Informação não disponível & $\begin{array}{lr}\text { Informação } & \text { não } \\
\text { disponível, } & \text { nem } \\
\text { referenciada } & \end{array}$ & $\begin{array}{lr}\text { Informação } & \text { não } \\
\text { disponível, } & \text { nem } \\
\text { referenciada } & \end{array}$ \\
\hline $\begin{array}{ll}\text { Viagens } & \text { de } \\
\text { caminhões }\end{array}$ & Informação não disponível & $\begin{array}{lr}\text { Informação } & \text { não } \\
\text { disponível, } & \text { nem } \\
\text { referenciada } & \end{array}$ & $\begin{array}{l}\text { Informação } \\
\text { disponível, } \\
\text { referenciada }\end{array}$ \\
\hline $\begin{array}{l}\text { Ocupação dos } \\
\text { veículos }\end{array}$ & Informação não disponível & $\begin{array}{lr}\text { Informação } & \text { não } \\
\text { disponível, } & \text { nem } \\
\text { referenciada } & \end{array}$ & $\begin{array}{l}\text { Informação } \\
\text { disponível, } \\
\text { referenciada }\end{array}$ \\
\hline $\begin{array}{l}\text { Horas pico do } \\
\text { gerador }\end{array}$ & $\begin{array}{l}\text { Em dias úteis a hora de pico da } \\
\text { manhã ocorre no período das } \\
10 \mathrm{~h} \text { às } 11 \mathrm{~h} \text {. A hora-pico da } \\
\text { tarde ocorre no período das } 12 \mathrm{~h} \\
\text { às } 13 \mathrm{~h} \text {. }\end{array}$ & $\begin{array}{lr}\text { Informação } & \text { não } \\
\text { disponível, } & \text { nem } \\
\text { referenciada } & \end{array}$ & $\begin{array}{l}\text { Informação } \\
\text { disponível, } \\
\text { referenciada }\end{array}$ \\
\hline $\begin{array}{l}\text { Realização dos } \\
\text { estudos }\end{array}$ & $\begin{array}{l}\text { Estudo para definição da hora- } \\
\text { pico do gerador foi realizado no } \\
\text { ano de } 1973 \text { em uma pequena } \\
\text { universidade, com } 545 \\
\text { estudantes, localizada } \\
\text { Delaware. }\end{array}$ & $\begin{array}{l}\text { ITE 2003: } 1970- \\
\text { 1990, ITE 2008: } \\
\text { 1970 - 2000. Em } \\
\text { locais distribuídos ao } \\
\text { longo dos Estados } \\
\text { Unidos. }\end{array}$ & $\begin{array}{l}1970-2000 \text { em locais } \\
\text { distribuídos ao longo dos } \\
\text { Estados Unidos. }\end{array}$ \\
\hline $\begin{array}{l}\text { Número de } \\
\text { viagens nos } \\
\text { finais de } \\
\text { semana }\end{array}$ & $\begin{array}{l}\text { Informação não disponível, nem } \\
\text { referenciada }\end{array}$ & \multicolumn{2}{|c|}{$\begin{array}{l}\text { A geração de viagens nos períodos em finais de } \\
\text { semana varia consideravelmente e, por isso, as } \\
\text { estatísticas referentes a esses períodos devem ser } \\
\text { utilizadas com cautela. }\end{array}$} \\
\hline $\begin{array}{l}\text { Recomendação } \\
\text { geral }\end{array}$ & \multicolumn{3}{|c|}{$\begin{array}{l}\text { Existe grande variação entre as áreas edificadas, a quantidade de empregados e a } \\
\text { disponibilidade de estacionamentos com relação às características socioeconômicas da } \\
\text { área atendida. Por essa razão, o número de estudantes é considerado como variável } \\
\text { independente mais confiável para a estimativa das taxas de geração de viagens. }\end{array}$} \\
\hline $\begin{array}{l}\text { Recomendação } \\
\text { referente à } \\
\text { disponibilidade } \\
\text { de transporte } \\
\text { público }\end{array}$ & $\begin{array}{l}\text { Informação não disponível, nem } \\
\text { referenciada }\end{array}$ & $\begin{array}{l}\text { Informação } \\
\text { disponível, } \\
\text { referenciada }\end{array}$ & $\begin{array}{l}\text { Muitos estudos não } \\
\text { indicaram a existência de } \\
\text { disponibilidade e o tipo de } \\
\text { transporte público. O ITE } \\
\text { considera que é importante } \\
\text { que esta informação seja } \\
\text { fornecida no futuro, e } \\
\text { indica que as taxas de } \\
\text { geração devem ser } \\
\text { consideradas com cautela. }\end{array}$ \\
\hline
\end{tabular}


Tabela 5 - Quantidade de estudos realizados para Universidades

\begin{tabular}{c|c|c|c|c|c}
\hline $\begin{array}{c}\text { Variável } \\
\text { Independente }(\mathrm{X})\end{array}$ & Período de tempo & ITE, 1991 & ITE, 2003 & ITE, 2008 & ITE, 2012 \\
\hline \multirow{5}{*}{ Estudantes } & Dia útil & 5 & 7 & 7 & 9 \\
\cline { 2 - 6 } & $(1)$ & 4 & 6 & 6 & 8 \\
\cline { 2 - 6 } & $(2)$ & 4 & 7 & 8 & 10 \\
\cline { 2 - 6 } & $(3)$ & 5 & 5 & 5 & 7 \\
\cline { 2 - 6 } & $(4)$ & 5 & 5 & 2 & 2 \\
\hline \multirow{5}{*}{ Empregados } & Sábado & 5 & 5 & 5 & 6 \\
\cline { 2 - 6 } & Dia útil & 4 & 4 & 4 & 7 \\
\cline { 2 - 6 } & $(1)$ & 5 & 5 & 5 & 7 \\
\cline { 2 - 6 } & $(2)$ & 5 & 5 & 5 & 2 \\
\cline { 2 - 6 } & $(3)$ & 2 & 2 & 2 & 7 \\
\hline
\end{tabular}

Legenda:

(1) Dia útil, hora-pico da manhã do tráfego da via adjacente

(2) Dia útil, hora-pico da tarde do tráfego da via adjacente

(3) Dia útil, hora-pico da manhã do gerador

(4) Dia útil, hora-pico da tarde do gerador

A Tabela 6 apresenta os valores das variáveis independentes referentes aos estudos considerados nas edições analisadas, para as duas variáveis independentes, referentes aos períodos de hora-pico da manhã e da tarde do gerador, em dia útil. Para esses períodos, ocorre variação somente na Edição 2012, em função da incorporação de estudos com maior número de estudantes e empregados.

Tabela 6 - Dados gerais das Universidades estudadas referentes ao gerador

\begin{tabular}{|c|c|c|c|c|c|}
\hline \multirow{2}{*}{$\begin{array}{c}\text { Variável } \\
\text { Independente } \\
\text { (X) }\end{array}$} & \multirow{2}{*}{$\begin{array}{l}\text { Período de } \\
\text { tempo }\end{array}$} & \multirow{2}{*}{$\begin{array}{l}\text { Edição ITE } \\
\quad \text { (Ano) }\end{array}$} & \multicolumn{3}{|c|}{ Valor da variável independente (X) } \\
\hline & & & Média & Mínimo(*) & Máximo(*) \\
\hline \multirow{8}{*}{ Estudantes } & \multirow{4}{*}{$\begin{array}{l}\text { Dia útil, hora- } \\
\text { pico da manhã } \\
\text { do gerador }\end{array}$} & 1991 & 2463 & 550 & 5300 \\
\hline & & 2003 & 2463 & 550 & 5300 \\
\hline & & 2008 & 2463 & 550 & 5300 \\
\hline & & 2012 & 8860 & 550 & 27500 \\
\hline & \multirow{4}{*}{$\begin{array}{l}\text { Dia útil, hora- } \\
\text { pico da tarde } \\
\text { do gerador }\end{array}$} & 1991 & 2463 & 550 & 5300 \\
\hline & & 2003 & 2463 & 550 & 5300 \\
\hline & & 2008 & 2463 & 550 & 5300 \\
\hline & & 2012 & 8860 & 550 & 27500 \\
\hline \multirow{8}{*}{ Empregados } & \multirow{4}{*}{$\begin{array}{l}\text { Dia útil, hora- } \\
\text { pico da manhã } \\
\text { do gerador }\end{array}$} & 1991 & 639 & 80 & 2050 \\
\hline & & 2003 & 639 & 80 & 2050 \\
\hline & & 2008 & 639 & 80 & 2050 \\
\hline & & 2012 & 1596 & 80 & 5800 \\
\hline & \multirow{4}{*}{$\begin{array}{l}\text { Dia útil, hora- } \\
\text { pico da tarde } \\
\text { do gerador }\end{array}$} & 1991 & 639 & 80 & 2050 \\
\hline & & 2003 & 639 & 80 & 2050 \\
\hline & & 2008 & 639 & 80 & 2050 \\
\hline & & 2012 & 1596 & 80 & 5800 \\
\hline
\end{tabular}

Legenda: (*) Valor estimado a partir dos gráficos apresentados no manual Trip Generation 
A Tabela 7, por sua vez, apresenta os valores das variáveis independentes referentes aos períodos de hora-pico da manhã e tarde da via adjacente, em dia útil. Para a variável independente “estudantes”, é possível verificar que houve, em geral, um aumento do valor médio, possivelmente fruto da maior variação entre o número de estudos que tratavam dessa variável entre as edições analisadas. As edições mais recentes incorporam estabelecimentos com maior quantidade de estudantes. Para a variável independente "empregados", a única variação observada é com relação à Edição 2012, que agregou estudos envolvendo estabelecimentos com maior quantidade de empregados.

Tabela 7 - Dados gerais das Universidades estudadas referentes à via adjacente

\begin{tabular}{|c|c|c|c|c|c|}
\hline \multirow{2}{*}{$\begin{array}{c}\text { Variável } \\
\text { Independente } \\
\text { (X) }\end{array}$} & \multirow{2}{*}{$\begin{array}{l}\text { Período de } \\
\text { tempo }\end{array}$} & \multirow{2}{*}{$\begin{array}{c}\text { Edição ITE } \\
\text { (Ano) }\end{array}$} & \multicolumn{3}{|c|}{ Valor da variável independente (X) } \\
\hline & & & Média & Mínimo(*) & Máximo(*) \\
\hline \multirow{8}{*}{ Estudantes } & \multirow{4}{*}{$\begin{array}{l}\text { Dia útil, hora- } \\
\text { pico da manhã } \\
\text { da via } \\
\text { adjacente }\end{array}$} & 1991 & 2943 & 700 & 5300 \\
\hline & & 2003 & 9545 & 700 & 37000 \\
\hline & & 2008 & 9545 & 700 & 37000 \\
\hline & & 2012 & 13372 & 700 & 37000 \\
\hline & \multirow{4}{*}{$\begin{array}{l}\text { Dia útil, hora- } \\
\text { pico da tarde } \\
\text { da via } \\
\text { adjacente }\end{array}$} & 1991 & 2943 & 700 & 5300 \\
\hline & & 2003 & 8353 & 700 & 37000 \\
\hline & & 2008 & 7327 & 700 & 37000 \\
\hline & & 2012 & 10832 & 700 & 37000 \\
\hline \multirow{8}{*}{ Empregados } & \multirow{4}{*}{$\begin{array}{l}\text { Dia útil, hora- } \\
\text { pico da manhã } \\
\text { da via } \\
\text { adjacente }\end{array}$} & 1991 & 779 & 120 & 2050 \\
\hline & & 2003 & 779 & 120 & 2050 \\
\hline & & 2008 & 779 & 120 & 2050 \\
\hline & & 2012 & 1849 & 120 & 5800 \\
\hline & \multirow{4}{*}{$\begin{array}{l}\text { Dia útil, hora- } \\
\text { pico da tarde } \\
\text { da via } \\
\text { adjacente }\end{array}$} & 1991 & 779 & 120 & 2050 \\
\hline & & 2003 & 779 & 120 & 2050 \\
\hline & & 2008 & 779 & 120 & 2050 \\
\hline & & 2012 & 1849 & 120 & 5800 \\
\hline
\end{tabular}

\section{Análise das taxas e modelos}

Para cada variável independente e período de tempo analisado, o ITE apresenta o número de estudos, o valor médio da variável independente, a distribuição direcional das viagens, a taxa média de geração de viagens, o intervalo de variação dessa taxa (valores mínimo e máximo) e o seu desvio-padrão nas instituições consideradas nos referidos estudos. Nas subseções a 
seguir estes valores, referentes às Instituições de Ensino Médio (IEMs) e Universidades, são apresentados e analisados sob a perspectiva da evolução ao longo do tempo.

\subsection{Instituições de Ensino Médio (IEMs) - Uso do Solo 530 do ITE}

As taxas médias e os correspondentes desvios-padrão para as Instituições de Ensino Médio (IEMs), publicadas nas Edições 1991, 2003, 2008 e 2012 são apresentadas na Tabela 8. Resultado do grande acréscimo no número de estudos considerados nas Edições 1991 e 2003, a diferença entre as taxas médias nessas duas edições é elevada, mantendo-se com pouca alteração nas edições subsequentes analisadas. A diferença entre as taxas de 1991 e 2003 pode ser melhor analisada com base na Tabela 9.

Tabela 8 - Taxas médias e desvios-padrão para o uso do solo IEMs (530)

\begin{tabular}{|c|c|c|c|c|c|c|c|c|c|}
\hline \multirow{2}{*}{$\begin{array}{c}\text { Variável } \\
\text { Independente }(\mathrm{X})\end{array}$} & \multirow{2}{*}{$\begin{array}{l}\text { Período } \\
\text { de tempo }\end{array}$} & \multicolumn{2}{|c|}{ ITE, 1991} & \multicolumn{2}{|c|}{ ITE, 2003} & \multicolumn{2}{|c|}{ ITE, 2008} & \multicolumn{2}{|c|}{ ITE, 2012} \\
\hline & & TM & DP & TM & DP & TM & DP & TM & DP \\
\hline \multirow{6}{*}{ Estudantes } & Dia útil & 1,38 & 1,27 & 1,71 & 1,49 & 1,71 & 1,49 & 1,71 & 1,49 \\
\hline & (1) & 0,41 & 0,67 & nd & nd & nd & nd & nd & nd \\
\hline & (2) & 0,08 & 0,30 & 0,14 & 0,38 & 0,13 & 0,37 & 0,13 & 0,37 \\
\hline & (3) & 0,30 & 0,55 & 0,41 & 0,67 & 0,42 & 0,68 & 0,43 & 0,69 \\
\hline & (4) & 0,23 & 0,49 & 0,28 & 0,54 & 0,29 & 0,55 & 0,29 & 0,55 \\
\hline & Sábado & 0,77 & nd & 0,61 & 0,88 & 0,61 & 0,88 & 0,61 & 0,88 \\
\hline \multirow{6}{*}{ Empregados } & Dia útil & 16,79 & 7,29 & 19,74 & 7,95 & 19,74 & 7,95 & 19,74 & 7,95 \\
\hline & (1) & 2,11 & nd & nd & nd & nd & nd & nd & nd \\
\hline & (2) & 0,83 & nd & 1,55 & 1,39 & 1,55 & 1,39 & 1,55 & 1,39 \\
\hline & (3) & 3,58 & 2,28 & 4,63 & 2,84 & 4,68 & 2,88 & 4,68 & 2,88 \\
\hline & (4) & 2,87 & 2,01 & 3,21 & 2,06 & 3,23 & 2,08 & 3,23 & 2,08 \\
\hline & Sábado & nd & nd & 6,57 & 5,21 & 6,57 & 5,21 & 6,57 & 5,21 \\
\hline \multirow{5}{*}{$\begin{array}{c}1000 \text { pés }^{2} \\
\text { (aproximadamente } \\
\left.92,90 \mathrm{~m}^{2}\right) \text { de área } \\
\text { bruta construída } \\
\text { (GFA) }\end{array}$} & Dia útil & 10,90 & 5,86 & 12,89 & 7,17 & 12,89 & 7,17 & 12,89 & 7,17 \\
\hline & (1) & 2,16 & nd & nd & nd & nd & nd & nd & nd \\
\hline & (2) & 0,84 & nd & 0,97 & 1,11 & 0,97 & 1,11 & 0,97 & 1,11 \\
\hline & (3) & 2,34 & 1,75 & 3,06 & 2,36 & 3,06 & 2,36 & 3,06 & 2,36 \\
\hline & (4) & 1,94 & 1,65 & 2,12 & 1,74 & 2,12 & 1,74 & 2,12 & 1,74 \\
\hline $\begin{array}{l}\text { Legenda: } \\
\text { (1) Dia útil, } \mathrm{h} \\
\text { (2) Dia útil, } \mathrm{h} \\
\text { (3) Dia útil, h } \\
\text { (4) Dia útil, h } \\
\text { nd = não disp } \\
\mathrm{TM}=\text { taxa mé } \\
\mathrm{DP}=\text { desvio- } \\
1 \text { pé quadrado }\end{array}$ & $\begin{array}{l}\text { ra-pico da } \\
\text { ra-pico da } 1 \\
\text { ra-pico da } \\
\text { nível } \\
\text { lia } \\
\text { adrão } \\
=0,092903\end{array}$ & $\begin{array}{l}\text { de do tra do } \\
\text { de deã do } \\
\text { de do g }\end{array}$ & $\begin{array}{l}\text { go da } \\
\text { ador } \\
\text { dor }\end{array}$ & $\begin{array}{l}\text { a adjac } \\
\text { adjace }\end{array}$ & & & & & \\
\hline
\end{tabular}


Todas as taxas apresentadas em 2003 sofreram um grande aumento percentual, exceto para o período de sábado. Não fica explícito se esta diferença expressa uma mudança comportamental no uso do automóvel para a realização de viagens nas IEMs ao longo de 12 anos, ou se trata apenas de um ajuste de representação do comportamento médio dos usuários das IEMs.

Tabela 9 - Comparação entre as taxas médias do ITE 1991 e 2003 para IEMs

\begin{tabular}{|c|c|c|c|c|c|}
\hline \multirow{2}{*}{$\begin{array}{c}\text { Variável } \\
\text { Independente }(\mathrm{X})\end{array}$} & \multirow{2}{*}{ Período de tempo } & \multicolumn{2}{|c|}{ Taxa Média } & \multicolumn{2}{|c|}{ Diferença } \\
\hline & & ITE, 1991 & ITE, 2003 & Valor & Percentagem \\
\hline \multirow{6}{*}{ Estudantes } & Dia útil & 1,38 & 1,71 & 0,33 & $23,91 \%$ \\
\hline & $(1)$ & 0,41 & nd & & \\
\hline & (2) & 0,08 & 0,14 & 0,06 & $75,00 \%$ \\
\hline & (3) & 0,30 & 0,41 & 0,11 & $36,67 \%$ \\
\hline & (4) & 0,23 & 0,28 & 0,05 & $21,74 \%$ \\
\hline & Sábado & 0,77 & 0,61 & $-0,16$ & $-20,78 \%$ \\
\hline \multirow{6}{*}{ Empregados } & Dia útil & 16,79 & 19,74 & 2,95 & $17,57 \%$ \\
\hline & $(1)$ & 2,11 & nd & & \\
\hline & (2) & 0,83 & 1,55 & 0,72 & $86,75 \%$ \\
\hline & (3) & 3,58 & 4,63 & 1,05 & $29,33 \%$ \\
\hline & $(4)$ & 2,87 & 3,21 & 0,34 & $11,85 \%$ \\
\hline & Sábado & & 6,57 & & \\
\hline \multirow{5}{*}{$\begin{array}{c}1000 \text { pés }^{2} \\
\text { (aproximadamente } \\
92,90 \mathrm{~m}^{2} \text { ) de área } \\
\text { bruta construída } \\
\text { (GFA) }\end{array}$} & Dia útil & 10,90 & 12,89 & 1,99 & $18,25 \%$ \\
\hline & (1) & 2,16 & nd & & \\
\hline & (2) & 0,84 & 0,97 & 0,13 & $15,48 \%$ \\
\hline & (3) & 2,34 & 3,06 & 0,72 & $30,77 \%$ \\
\hline & (4) & 1,94 & 2,12 & 0,18 & $9,3 \%$ \\
\hline \multicolumn{6}{|c|}{$\begin{array}{l}\text { Legenda: } \\
\text { (1) Dia útil, hora-pico da manhã do tráfego } \\
\text { (2) Dia útil, hora-pico da tarde do tráfego da } \\
\text { (3) Dia útil, hora-pico da manhã do gerador } \\
\text { (4) Dia útil, hora-pico da tarde do gerador } \\
1 \text { pé quadrado }=0,092903 \mathrm{~m}^{2}\end{array}$} \\
\hline
\end{tabular}

Com relação aos modelos de geração de viagens, chama a atenção o fato de que na Edição 1991 foram apresentados modelos para todos os períodos em que o número de estudos considerados foi igual ou superior a 20. Assim, para todas as variáveis independentes, foram apresentados modelos para: dia útil; dia útil, hora-pico da manhã do gerador; e dia útil, horapico da tarde do gerador. Esses modelos assumiram formas funcionais distintas para cada tipo de variável independente. Para a variável "estudantes", foi adotada uma função inversa, na forma mostrada na Equação (1). Para as variáveis “empregados” e “área construída', as formas adotadas foram a linear e a logarítmica, respectivamente. 


$$
Y=\frac{1}{\frac{\alpha}{X}+\beta}
$$

em que:

$\mathrm{Y}=$ número estimado total de viagens;

$\mathrm{X}=$ número de estudantes;

$\alpha$ e $\beta=$ parâmetros do modelo.

No caso da Edição 2003, só foram apresentados modelos para os períodos em que o número de observações foi igual ou superior a 51. No caso da variável "estudantes", isso significou modelos para todas as situações apresentadas em 1991, porém com a forma funcional logarítmica. Para a variável "empregados", somente foram apresentados modelos para os dias úteis e para a hora-pico da tarde do gerador, em dia útil, também com forma logarítmica. $\mathrm{Na}$ Edição 2008, os modelos apresentados são os mesmos desenvolvidos na versão de 2003, e apenas para os casos das variáveis "estudantes" e "empregados" para o período dia útil. Já no caso da publicação feita em 2012, somente foram apresentados dois modelos logarítmicos, relacionados à variável independente "estudantes", para os períodos dia útil e hora-pico da tarde do gerador, em dia útil. Para o período dia útil, o modelo de 2012 é exatamente o mesmo de 2003, uma vez que nenhum estudo novo foi considerado para o período entre esses dois anos. No caso do modelo para a hora-pico da tarde do gerador, o modelo de 2012 é bastante similar ao de 2003, embora o número de estudos agregados entre esses dois anos tenha sido de 12 (passou de 62 em 2003 para 74 em 2012).

No caso da variável "área", de 2003 a 2012, não foi apresentado nenhum modelo significativo. Para efeito de comparação entre os modelos, na Tabela 10 são apresentados os modelos referentes à variável independente "estudantes" para os períodos dia útil, hora-pico da manhã e hora-pico da tarde do gerador, em dia útil. 
Tabela 10 - Modelos de geração de viagens para Instituições de Ensino Médio

\begin{tabular}{|c|c|c|c|}
\hline Período & ITE, Ano & Modelo & $\mathrm{R}^{2}$ \\
\hline \multirow{4}{*}{ Dia útil } & 1991 & $\mathrm{Y}=[(0,420 / \mathrm{X})+0,00027]^{-1}$ & 0,82 \\
\hline & 2003 & $\operatorname{Ln}(Y)=0,81 \operatorname{Ln}(X)+1,86$ & 0,54 \\
\hline & 2008 & $\operatorname{Ln}(Y)=0,81 \operatorname{Ln}(X)+1,86$ & 0,54 \\
\hline & 2012 & $\operatorname{Ln}(Y)=0,81 \operatorname{Ln}(X)+1,86$ & 0,54 \\
\hline \multirow{4}{*}{ (a) } & 1991 & $\mathrm{Y}=[(3,357 / \mathrm{X})-0,00011]^{-1}$ & 0,87 \\
\hline & 2003 & $\operatorname{Ln}(Y)=0,77 \operatorname{Ln}(X)+0,69$ & 0,50 \\
\hline & 2008 & nd & \\
\hline & 2012 & nd & \\
\hline \multirow{4}{*}{ (b) } & 1991 & $\mathrm{Y}=[(1,460 / \mathrm{X})+0,00246]^{-1}$ & 0,59 \\
\hline & 2003 & $\operatorname{Ln}(Y)=0,62 \operatorname{Ln}(X)+1,45$ & 0,51 \\
\hline & 2008 & nd & \\
\hline & 2012 & $\operatorname{Ln}(Y)=0,61 \operatorname{Ln}(X)+1,52$ & 0,51 \\
\hline
\end{tabular}

Legenda:

$\mathrm{X}=$ número de estudantes (variável independente)

(a) Dia útil, hora-pico da manhã do gerador

(b) Dia útil, hora-pico da tarde do gerador

nd = modelo não disponível

\subsection{Universidades - Uso do Solo 550 do ITE}

A Tabela 11 mostra as taxas médias ponderadas e os correspondentes desvios-padrões para as publicações do ITE dos anos 1991, 2003, 2008 e 2012.

Tabela 11 - Taxas médias e desvios-padrão para o uso do solo Universidades (550)

\begin{tabular}{|c|c|c|c|c|c|c|c|c|c|}
\hline \multirow{2}{*}{$\begin{array}{c}\text { Variável } \\
\text { Independente } \\
(\mathrm{X})\end{array}$} & \multirow{2}{*}{$\begin{array}{l}\text { Período } \\
\text { de tempo }\end{array}$} & \multicolumn{2}{|c|}{ ITE, 1991} & \multicolumn{2}{|c|}{ ITE, 2003} & \multicolumn{2}{|c|}{ ITE, 2008} & \multicolumn{2}{|c|}{ ITE, 2012} \\
\hline & & TM. & DP & $\mathrm{TM}$ & DP & $\mathrm{TM}$ & DP & $\mathrm{TM}$ & DP \\
\hline \multirow{6}{*}{ Estudantes } & Dia útil & 2,37 & 1,56 & 2,38 & 1,57 & 2,38 & 1,57 & 1,71 & 1,39 \\
\hline & (1) & 0,19 & 0,44 & 0,21 & 0,46 & 0,21 & 0,46 & 0,17 & 0,41 \\
\hline & (2) & 0,23 & 0,49 & 0,21 & 0,46 & 0,21 & 0,46 & 0,17 & 0,42 \\
\hline & (3) & 0,2 & 0,45 & 0,2 & 0,45 & 0,2 & 0,45 & 0,14 & 0,38 \\
\hline & (4) & 0,24 & 0,49 & 0,24 & 0,49 & 0,24 & 0,49 & 0,15 & 0,39 \\
\hline & Sábado & 1,3 & & 1,3 & & 1,3 & & 1,3 & \\
\hline \multirow{6}{*}{ Empregados } & Dia útil & 9,13 & 7,03 & 9,13 & 7,03 & 9,13 & 7,03 & 8,96 & 4,96 \\
\hline & $(1)$ & 0,73 & 1,02 & 0,73 & 1,02 & 0,73 & 1,02 & 0,75 & 0,92 \\
\hline & (2) & 0,88 & 1,15 & 0,88 & 1,15 & 0,88 & 1,15 & 0,79 & 0,97 \\
\hline & (3) & 0,78 & 1,07 & 0,78 & 1,07 & 0,78 & 1,07 & 0,79 & 0,95 \\
\hline & (4) & 0,91 & 1,17 & 0,91 & 1,17 & 0,91 & 1,17 & 0,85 & 1 \\
\hline & Sábado & 3,12 & & 3,12 & & 3,12 & & 3,12 & \\
\hline $\begin{array}{l}\text { Legenda: } \\
\text { (5) Dia } \\
\text { (6) Dia } \\
\text { (7) Dia } \\
\text { (8) Dia } \\
\text { TM = ta } \\
\text { DP = de }\end{array}$ & $\begin{array}{l}\text { il, hora-picc } \\
\text { il, hora-picc } \\
\text { il, hora-picc } \\
\text { il, hora-picc } \\
\text { média } \\
\text { io-padrão }\end{array}$ & $\begin{array}{l}\text { la man } \\
\text { la tard } \\
\text { la man } \\
\text { la tard }\end{array}$ & $\begin{array}{l}\text { lo tráf } \\
\text { tráfeg } \\
\text { lo gera } \\
\text { gerad }\end{array}$ & $\begin{array}{l}\text { da via } \\
\text { via a }\end{array}$ & $\begin{array}{l}\text { acente } \\
\text { ente }\end{array}$ & & & & \\
\hline
\end{tabular}


Os dados apresentados revelam que a variação entre as edições de 1991 e 2008 são mínimas. No entanto, as taxas publicadas em 2012 para a variável independente "estudantes" são significativamente menores do que as taxas correspondentes publicadas no ano de 2008 . A Tabela 12 mostra esta comparação em termos absolutos e percentuais, e não inclui as taxas correspondentes aos sábados, uma vez que essas taxas foram determinadas com dados anteriores a 1991, e não sofreram qualquer modificação em 2003, 2008 e 2012.

Para permitir uma comparação gráfica entre as taxas médias, taxas mínimas, taxas máximas e desvios-padrões, as Figuras 1 a 4 mostram a informação correspondente aos casos com maior variação na quantidade de estudos.

\section{Tabela 12 - Comparação entre as taxas médias do ITE 2008 e 2012 para Universidades}

\begin{tabular}{c|c|c|c|c|c}
\hline \multirow{2}{*}{$\begin{array}{c}\text { Variável } \\
\text { Independente } \\
(\mathrm{X})\end{array}$} & Período de tempo & \multicolumn{2}{|c|}{ Taxa Média } & \multicolumn{2}{c}{ Diferença } \\
\cline { 3 - 6 } & & ITE, 2008 & ITE, 2012 & Valor & Percentagem \\
\hline \multirow{4}{*}{ Estudantes } & Dia útil & 2,38 & 1,71 & $-0,67$ & $-28,15 \%$ \\
\cline { 2 - 5 } & $(1)$ & 0,21 & 0,17 & $-0,04$ & $-19,05 \%$ \\
\cline { 2 - 5 } & $(2)$ & 0,21 & 0,17 & $-0,04$ & $-19,05 \%$ \\
\cline { 2 - 5 } & $(3)$ & 0,2 & 0,14 & $-0,06$ & $-30,00 \%$ \\
\hline \multirow{4}{*}{ Empregados } & $(4)$ & 0,24 & 0,15 & $-0,09$ & $-37,50 \%$ \\
\cline { 2 - 6 } & Dia útil & 9,13 & 8,96 & $-0,17$ & $-1,86 \%$ \\
\cline { 2 - 6 } & $(1)$ & 0,73 & 0,75 & 0,02 & $2,74 \%$ \\
\cline { 2 - 6 } & $(2)$ & 0,88 & 0,79 & $-0,09$ & $-10,23$ \\
\cline { 2 - 6 } & $(3)$ & 0,78 & 0,79 & 0,01 & $1,28 \%$ \\
\hline
\end{tabular}

Legenda:

(c) Dia útil, hora-pico da manhã do tráfego da via adjacente

(d) Dia útil, hora-pico da tarde do tráfego da via adjacente

(e) Dia útil, hora-pico da manhã do gerador

(f) Dia útil, hora-pico da tarde do gerador

Para a variável independente "estudantes", a Figura 1 mostra as comparações para a hora-pico da manhã do tráfego da via adjacente, período para o qual a quantidade de estudos passou de 4 em 1991 para 6 em 2003 e 2008 e 8 em 2012. A Figura 2 fornece comparação similar para a hora-pico da tarde do tráfego da via adjacente, período no qual a quantidade de estudos passou de 4 em 1991 para 7 em 2003, 8 em 2008 e 10 em 2012. 


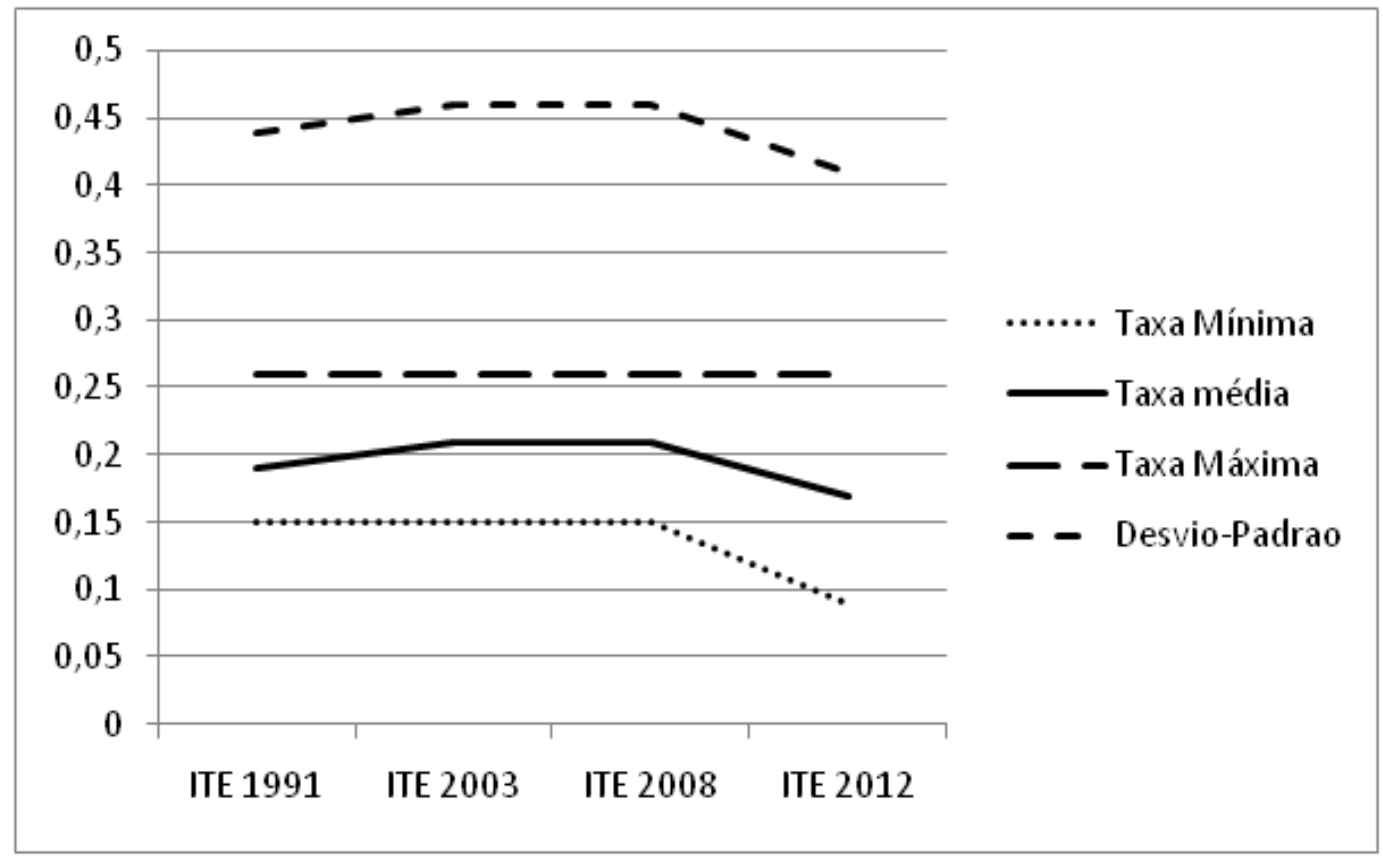

Figura 1 - Variável independente "estudantes" para Universidades: hora-pico da manhã na via adjacente

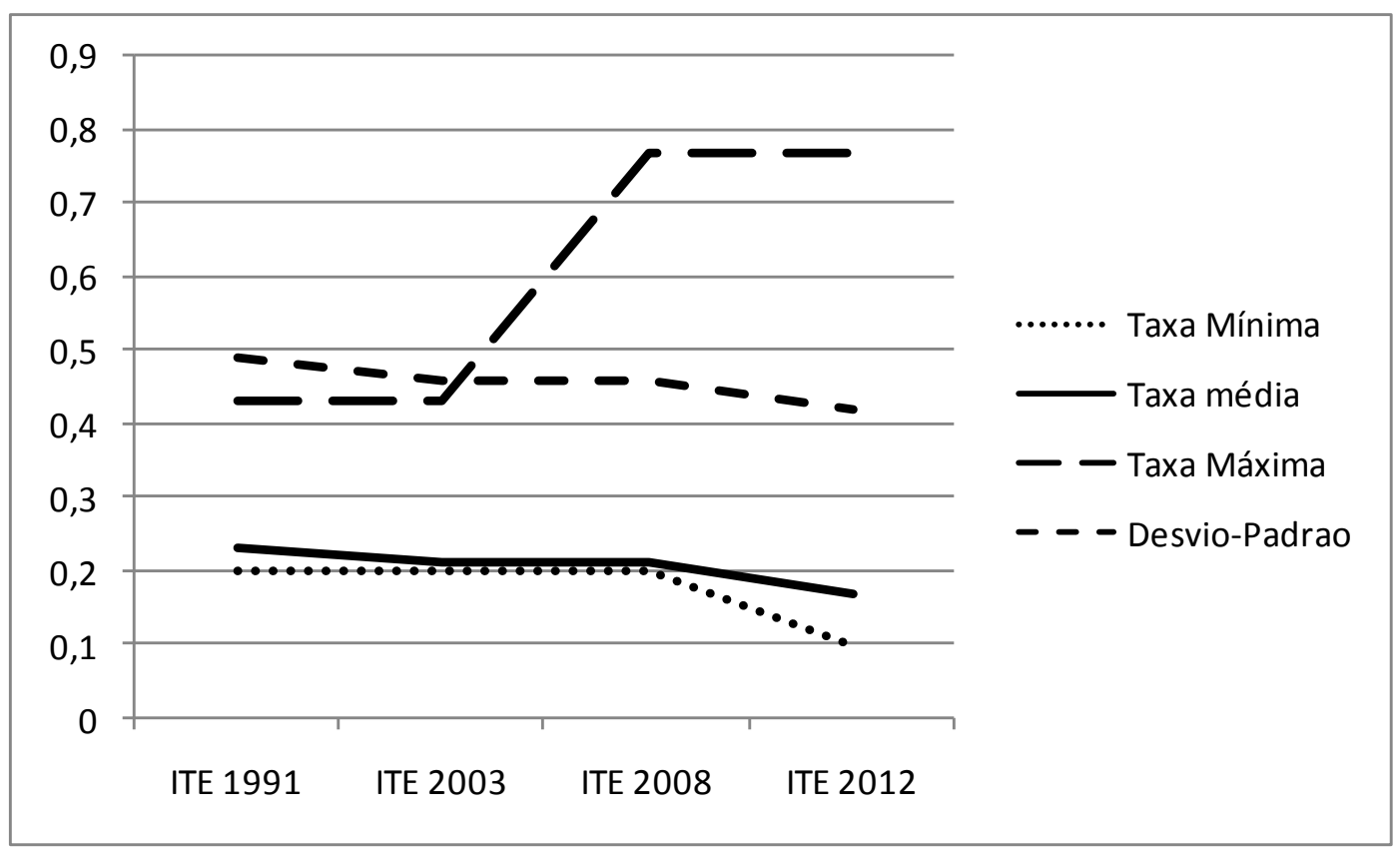

Figura 2 - Variável independente "estudantes" para Universidades: hora-pico da tarde na via adjacente 
Para a variável independente "empregados", a Figura 3 mostra as comparações realizadas para a hora-pico da tarde do tráfego na via adjacente. Nesse período, a quantidade de estudos passou de 4 em 2008 para 6 em 2012.

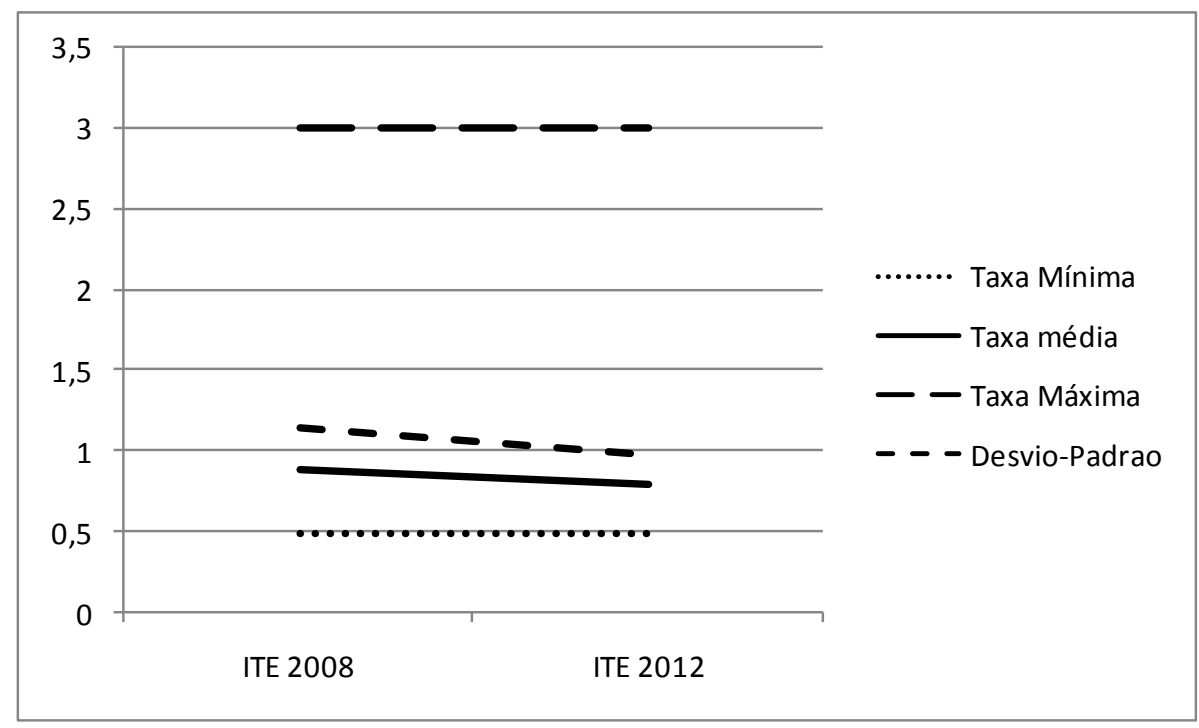

Figura 3 - Variável independente "empregados" para Universidades: hora-pico da tarde na via adjacente

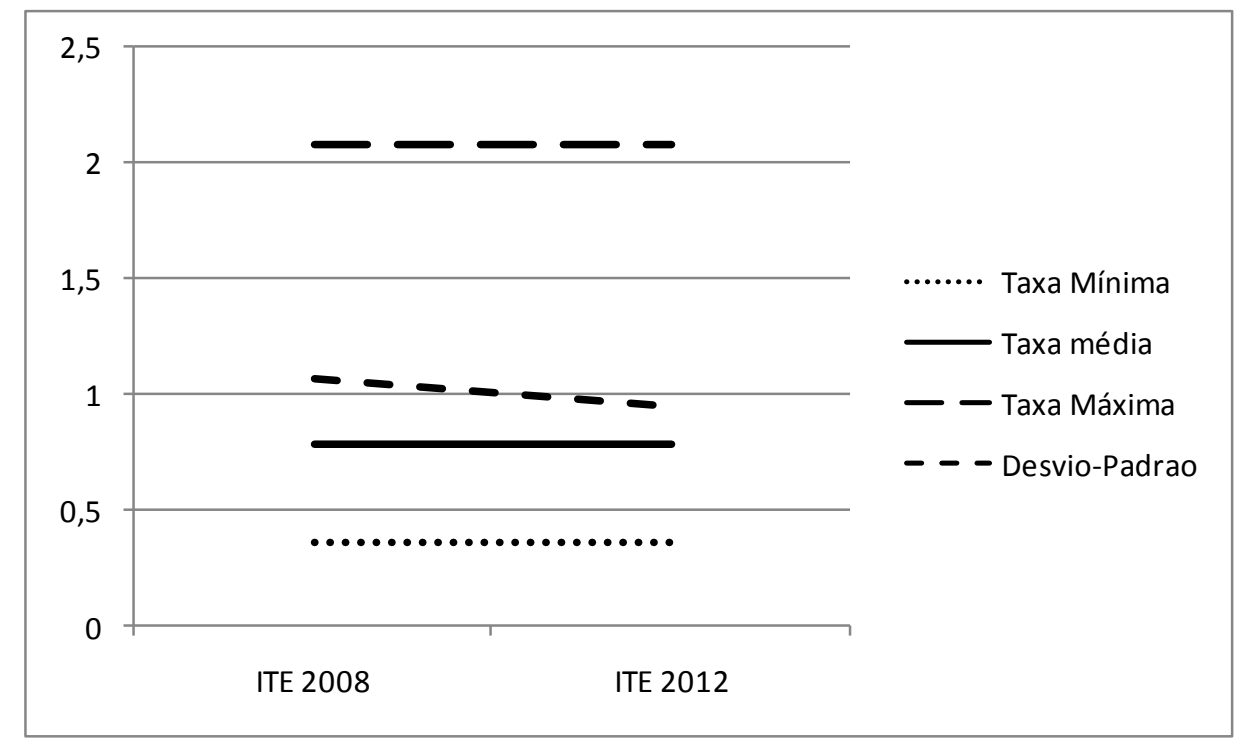

Figura 4 - Variável independente "empregados" para Universidades: hora-pico da manhã do gerador 
A Figura 4, por sua vez, mostra as comparações para a hora-pico da manhã do polo gerador, período em que a quantidade de estudos passou de 6 em 2008 para 8 em 2012. Em ambos os casos, as publicações de 1991 e 2003 não são referidas por não apresentarem mudanças com relação à de 2008.

As taxas médias correspondentes à variável independente "estudantes", em todos os períodos de tempo analisados, mostram importantes reduções entre 2008 e 2012. Em média, essas reduções são superiores a 25\% e, para as horas de pico do gerador, são superiores a 30\%. Para a variável independente "empregados", a variação é muito menos destacada, sendo que, em média, as taxas somente diminuíram na ordem de $3 \%$ e, em alguns casos, apresentam um pequeno incremento.

Cabe registrar que as taxas de geração de viagens publicadas pelo ITE correspondem às estatísticas obtidas com todos os estudos aceitos até a data da publicação. Isto é, a incorporação de estudos se dá progressivamente e as taxas publicadas em edições mais recentes também levam em conta os estudos anteriores. O ITE apresenta gráficos que relacionam as viagens veiculares (por automóvel) com a variável independente considerada, nos quais cada estudo está representado por um ponto. No caso das Universidades, em que o número total de estudos não é elevado, esses gráficos permitem comparar as diferentes adições, identificar quais são os novos estudos e, assim, obter a taxa média correspondente para esses estudos.

Conforme apresentado anteriormente, somente dois estudos foram incorporados entre os anos de 2008 e 2012, e as taxas médias correspondentes a esses estudos estão incluídas na Tabela 13, na coluna denominada "Novos Estudos". 
Tabela 13 - Comparação entre as taxas médias do ITE 2008 e as dos novos estudos para Universidades

\begin{tabular}{|c|c|c|c|c|c|}
\hline \multirow{2}{*}{$\begin{array}{c}\text { Variável } \\
\text { Independente } \\
(\mathrm{X})\end{array}$} & \multirow[b]{2}{*}{ Período de tempo } & \multicolumn{2}{|c|}{ Taxa Média } & \multicolumn{2}{|c|}{ Diferença } \\
\hline & & ITE, 2008 & $\begin{array}{c}\text { Novos } \\
\text { Estudos }\end{array}$ & Valor & Percentagem \\
\hline \multirow{5}{*}{ Estudantes } & Dia útil & 2,38 & 1,42 & $-0,96$ & $-40,34 \%$ \\
\hline & $(1)$ & 0,21 & 0,12 & $-0,09$ & $-42,86 \%$ \\
\hline & $(2)$ & 0,21 & 0,12 & $-0,09$ & $-42,86 \%$ \\
\hline & (3) & 0,2 & 0,13 & $-0,07$ & $-35,00 \%$ \\
\hline & $(4)$ & 0,24 & 0,13 & $-0,11$ & $-45,83 \%$ \\
\hline \multirow{5}{*}{ Empregados } & Dia útil & 9,13 & 8,88 & $-0,25$ & $-2,74 \%$ \\
\hline & $(1)$ & 0,73 & 0,76 & 0,03 & $4,11 \%$ \\
\hline & $(2)$ & 0,88 & 0,75 & $-0,13$ & $-14,77 \%$ \\
\hline & $(3)$ & 0,78 & 0,79 & 0,01 & $1,28 \%$ \\
\hline & (4) & 0,91 & 0,81 & $-0,10$ & $-10,99 \%$ \\
\hline
\end{tabular}

Legenda:

(1) Dia útil, hora-pico da manhã do tráfego da via adjacente

(2) Dia útil, hora-pico da tarde do tráfego da via adjacente

(3) Dia útil, hora-pico da manhã do gerador

(4) Dia útil, hora-pico da tarde do gerador

É possível destacar que, para a variável independente “estudantes", os novos estudos apresentam taxas médias substancialmente menores, com reduções da ordem de $40 \%$ em relação às taxas correspondentes do ITE 2008. A Tabela 14 compara as taxas médias reportadas nas edições do ITE de 2008 e 2012, e as taxas estimadas para os novos estudos (incorporados entre 2008 e 2012).

Tabela 14 - Comparação das taxas médias para Universidades

- ITE 2008, 2012 e novos estudos

\begin{tabular}{c|c|c|c|c}
\hline \multirow{2}{*}{$\begin{array}{c}\text { Variável } \\
\text { Independente } \\
(\mathrm{X})\end{array}$} & Período de tempo & \multicolumn{3}{|c}{ Taxa Média } \\
\cline { 2 - 5 } & & ITE, 2008 & ITE, 2012 & Novos Estudos \\
\hline \multirow{4}{*}{ Estudantes } & Dia útil & 2,38 & 1,71 & 1,42 \\
\cline { 2 - 5 } & $(1)$ & 0,21 & 0,17 & 0,12 \\
\cline { 2 - 5 } & $(2)$ & 0,21 & 0,17 & 0,12 \\
\cline { 2 - 5 } & $(3)$ & 0,2 & 0,14 & 0,13 \\
\cline { 2 - 5 } & $(4)$ & 0,24 & 0,15 & 0,13 \\
\cline { 2 - 5 } & Dia útil & 9,13 & 8,96 & 8,88 \\
\cline { 2 - 5 } & $(1)$ & 0,73 & 0,75 & 0,76 \\
\cline { 2 - 5 } & $(2)$ & 0,88 & 0,79 & 0,75 \\
\cline { 2 - 5 } & $(3)$ & 0,91 & 0,79 & 0,79 \\
\hline \multirow{4}{*}{ Empregados } & $(4)$ & & & 0,81 \\
\hline
\end{tabular}

Legenda:

(1) Dia útil, hora-pico da manhã do tráfego da via adjacente

(2) Dia útil, hora-pico da tarde do tráfego da via adjacente

(3) Dia útil, hora-pico da manhã do gerador

(4) Dia útil, hora-pico da tarde do gerador 
A situação apresentada para a variável independente "empregados" é muito diferente, com poucas variações entre as taxas médias prévias e as taxas dos novos estudos. Em média, para os novos estudos, a redução das taxas médias em relação às correspondentes de ITE 2008 foi da ordem de 5\%. Segundo reportado na Seção 2.2, esta situação ocorre porque os novos estudos contemplam instituições com maior número de estudantes e empregados e com disponibilidade de serviços de transporte público.

Para a variável independente "estudantes" fica a dúvida sobre em que medida a destacada redução das taxas de geração é fruto da influência do tamanho dessa variável independente e/ou da disponibilidade de transporte público.

A comparação das taxas horárias com a taxa diária permite estimar o fator horário de pico (FHP). Nas diversas edições analisadas do ITE, tanto para a hora-pico da via adjacente quanto para a hora-pico do gerador, nos períodos da manhã e da tarde, o FHP se encontra entre 8 e $10 \%$, considerando-se as entradas e saídas em conjunto. Já com relação à distribuição direcional das viagens a situação é muito diferente. De 75 a $80 \%$ das viagens são de entrada nos horários de pico da manhã, e as viagens de saída são da ordem de $70 \%$ nos horários de pico da tarde.

Os modelos de geração de viagens, e os correspondentes coeficientes de determinação $\left(\mathrm{R}^{2}\right)$, apresentados nas quatro publicações analisadas são apresentados na Tabela 15.

Como era de se esperar, novamente se observa que as variações entre as edições de 1991 e 2008 foram mínimas. Já com relação à comparação entre os modelos apresentados nas edições de 2008 e 2012, as mudanças são relevantes. Essa comparação pode ser verificada na Tabela 16. De acordo com a tabela verifica-se que, por um lado, na publicação do ano 2008 todos os modelos correspondentes à variável independente "estudantes" apresentam forma funcional linear, com a única exceção do modelo para a hora-pico da manhã do gerador. Para a variável independente "empregados", por outro lado, os modelos apresentam a forma funcional logarítmica. 
Na edição publicada em 2012, oito dos dez modelos tiveram sua forma funcional alterada. Nessa publicação, todos os modelos da variável "estudantes" são logarítmicos e os modelos relacionados à variável empregados são lineares, com a única exceção do modelo para dias úteis. Quando o modelo é linear, a variável dependente cresce sempre a mesma taxa, definida pelo coeficiente da variável independente. Isto é, existe uma proporcionalidade direta entre as duas variáveis, somente modificada pela influência do termo constante.

No caso do modelo logarítmico, o coeficiente do logaritmo da variável independente define a proporcionalidade. Se ele é menor do que um, o crescimento da variável dependente é menos do que proporcional ao crescimento da variável independente; se é maior do que um, ocorre a situação inversa. É possível verificar que para todos os casos reportados na Tabela 16, o citado coeficiente é menor do que um (situa-se entre 0,52 e 0,74 para empregados e entre 0,73 e 0,88 para estudantes). Quer dizer, os modelos logarítmicos mostram um acréscimo da variável dependente menos que proporcional ao crescimento da variável independente.

Para a variável independente "estudantes", a mudança dos modelos lineares para logarítmicos implica em que os novos estabelecimentos incorporados reduzem a tendência de crescimento das viagens motorizadas por automóvel. Para a variável independente "empregados", destacase que, para todos os modelos lineares, o coeficiente obtido (entre 0,61 e 0,67) é sempre menor que a taxa média (entre 0,75 e 0,85 ). 
Tabela 15 - Modelos de geração de viagens e $\mathbf{R}^{2}$ para Universidades

\begin{tabular}{|c|c|c|c|c|c|c|c|c|c|}
\hline \multirow{2}{*}{$\begin{array}{c}\text { Variável } \\
\text { Independente } \\
\text { (X) }\end{array}$} & \multirow{2}{*}{$\begin{array}{l}\text { Período } \\
\text { de } \\
\text { tempo }\end{array}$} & \multicolumn{2}{|l|}{ ITE, 1991} & \multicolumn{2}{|l|}{ ITE, 2003} & \multicolumn{2}{|l|}{ ITE, 2008} & \multicolumn{2}{|l|}{ ITE, 2012} \\
\hline & & Modelo & $\mathrm{R}^{2}$ & Modelo & $\mathrm{R}^{2}$ & Modelo & $\mathrm{R}^{2}$ & Modelo & $\mathrm{R}^{2}$ \\
\hline \multirow{5}{*}{ Estudantes } & Dia útil & $Y=2,355(X)+31,862$ & 0,98 & $\begin{array}{c}\mathrm{Y}=2,23(\mathrm{X})+ \\
440,00\end{array}$ & 0,98 & $\begin{array}{c}\mathrm{Y}=2,23(\mathrm{X})+ \\
440,00\end{array}$ & 0,98 & $\operatorname{Ln}(Y)=0,86 \operatorname{Ln}(X)+1,93$ & 0,97 \\
\hline & (1) & $Y=0,184(X)-26,359$ & 0,92 & $Y=0,21(X)-69,14$ & 1,00 & $\begin{array}{c}Y=0,21(\mathrm{X})- \\
69,14\end{array}$ & 1,00 & $\operatorname{Ln}(Y)=0,88 \operatorname{Ln}(X)-0,68$ & 0,96 \\
\hline & (2) & $Y=0,188(X)+133,429$ & 0,97 & $\begin{array}{c}\mathrm{Y}=0,19(\mathrm{X})+ \\
125,35\end{array}$ & 1,00 & $\begin{array}{c}\mathrm{Y}=0,19(\mathrm{X})+ \\
118,58\end{array}$ & 1,00 & $\operatorname{Ln}(Y)=0,73 \operatorname{Ln}(X)+0,84$ & 0,96 \\
\hline & (3) & $Y=0,178(X)+58,63$ & 0,92 & $\begin{aligned} \operatorname{Ln}(Y) & =0,85 \operatorname{Ln}(X) \\
& -0,35\end{aligned}$ & 0,95 & $\begin{array}{l}\operatorname{Ln}(Y)=0,85 \\
\operatorname{Ln}(X)-0,35\end{array}$ & 0,95 & $\operatorname{Ln}(Y)=0,80 \operatorname{Ln}(X)-0,03$ & 0,97 \\
\hline & (4) & $Y=0,195(X)+100,481$ & 0,97 & $\begin{array}{c}\mathrm{Y}=0,20(\mathrm{X})+ \\
100,48\end{array}$ & 0,97 & $\begin{array}{c}\mathrm{Y}=0,20(\mathrm{X})+ \\
100,48\end{array}$ & 0,97 & $\operatorname{Ln}(Y)=0,77 \operatorname{Ln}(X)+0,38$ & 0,97 \\
\hline \multirow{5}{*}{ Empregados } & Dia útil & $\begin{array}{c}\operatorname{Ln}(Y)=0,741 \operatorname{Ln}(X)+ \\
3,915\end{array}$ & 0,78 & $\begin{aligned} \operatorname{Ln}(\mathrm{Y}) & =0,74 \operatorname{Ln}(\mathrm{X}) \\
& +3,92\end{aligned}$ & 0,78 & $\begin{array}{l}\operatorname{Ln}(Y)=0,74 \\
\operatorname{Ln}(X)+3,92\end{array}$ & 0,78 & $\operatorname{Ln}(Y)=0,84 \operatorname{Ln}(X)+3,43$ & 0,89 \\
\hline & (1) & $\operatorname{Ln}(Y)=0,64 \operatorname{Ln}(X)+2,084$ & 0,64 & $\begin{aligned} \operatorname{Ln}(Y) & =0,64 \operatorname{Ln}(X) \\
& +2,08\end{aligned}$ & 0,64 & $\begin{array}{l}\operatorname{Ln}(Y)=0,64 \\
\operatorname{Ln}(X)+2,08\end{array}$ & 0,64 & $Y=0,65(X)+198,53$ & 0,89 \\
\hline & (2) & & & $\begin{aligned} \operatorname{Ln}(Y) & =0,52 \operatorname{Ln}(X) \\
& +3,12\end{aligned}$ & 0,52 & $\begin{array}{l}\operatorname{Ln}(Y)=0,52 \\
\operatorname{Ln}(X)+3,12\end{array}$ & 0,52 & $Y=0,61(X)+343,53$ & 0,90 \\
\hline & (3) & $\begin{array}{c}\operatorname{Ln}(Y)=0,615 \operatorname{Ln}(X)+ \\
2,295\end{array}$ & 0,72 & $\begin{aligned} \operatorname{Ln}(Y) & =0,62 \operatorname{Ln}(X) \\
& +2,30\end{aligned}$ & 0,72 & $\begin{array}{l}\operatorname{Ln}(Y)=0,62 \\
\operatorname{Ln}(X)+2,30\end{array}$ & 0,72 & $Y=0,67(X)+188,73$ & 0,90 \\
\hline & (4) & $\begin{array}{c}\operatorname{Ln}(Y)=0,605 \operatorname{Ln}(X)+ \\
2,527\end{array}$ & 0,69 & $\begin{aligned} \operatorname{Ln}(Y) & =0,61 \operatorname{Ln}(X) \\
& +2,53\end{aligned}$ & 0,69 & $\begin{array}{l}\operatorname{Ln}(Y)=0,61 \\
\operatorname{Ln}(X)+2,53\end{array}$ & 0,69 & $Y=0,66(X)+291,57$ & 0,89 \\
\hline
\end{tabular}

Legenda:

(1) Dia útil, hora-pico da manhã do tráfego da via adjacente

(2) Dia útil, hora-pico da tarde do tráfego da via adjacente

(3) Dia útil, hora-pico da manhã do gerador

(4) Dia útil, hora-pico da tarde do gerador 
Tabela 16 - Comparação entre os modelos das edições de 2008 e 2012 -

Universidades

\begin{tabular}{|c|c|c|c|c|}
\hline \multirow{2}{*}{$\begin{array}{c}\text { Variável } \\
\text { Independente } \\
\text { (X) }\end{array}$} & \multirow[b]{2}{*}{ Período de tempo } & \multicolumn{2}{|c|}{ Modelo } & \multirow{2}{*}{$\begin{array}{c}\text { Mudança } \\
\text { de } \\
\text { função }\end{array}$} \\
\hline & & ITE, 2008 & ITE, 2012 & \\
\hline \multirow{5}{*}{ Estudantes } & Dia útil & $Y=2,23(X)+440,00$ & $\operatorname{Ln}(Y)=0,86 \operatorname{Ln}(X)+1,93$ & Sim \\
\hline & $(1)$ & $\mathrm{Y}=0,21(\mathrm{X})-69,14$ & $\operatorname{Ln}(Y)=0,88 \operatorname{Ln}(X)-0,68$ & Sim \\
\hline & $(2)$ & $Y=0,19(X)+118,58$ & $\operatorname{Ln}(Y)=0,73 \operatorname{Ln}(X)+0,84$ & Sim \\
\hline & (3) & $\operatorname{Ln}(Y)=0,85 \operatorname{Ln}(X)-0,35$ & $\operatorname{Ln}(Y)=0,80 \operatorname{Ln}(X)-0,03$ & Não \\
\hline & $(4)$ & $\mathrm{Y}=0,20(\mathrm{X})+100,48$ & $\operatorname{Ln}(Y)=0,77 \operatorname{Ln}(X)+0,38$ & Sim \\
\hline \multirow{5}{*}{ Empregados } & Dia útil & $\operatorname{Ln}(Y)=0,74 \operatorname{Ln}(X)+3,92$ & $\operatorname{Ln}(Y)=0,84 \operatorname{Ln}(X)+3,43$ & Não \\
\hline & $(1)$ & $\operatorname{Ln}(Y)=0,64 \operatorname{Ln}(X)+2,08$ & $\mathrm{Y}=0,65(\mathrm{X})+198,53$ & Sim \\
\hline & (2) & $\operatorname{Ln}(Y)=0,52 \operatorname{Ln}(X)+3,12$ & $Y=0,61(X)+343,53$ & Sim \\
\hline & $(3)$ & $\operatorname{Ln}(Y)=0,62 \operatorname{Ln}(X)+2,30$ & $Y=0,67(X)+188,73$ & Sim \\
\hline & (4) & $\operatorname{Ln}(Y)=0,61 \operatorname{Ln}(X)+2,53$ & $\mathrm{Y}=0,66(\mathrm{X})+291,57$ & Sim \\
\hline
\end{tabular}

Legenda:

(1) Dia útil, hora-pico da manhã do tráfego da via adjacente

(2) Dia útil, hora-pico da tarde do tráfego da via adjacente

(3) Dia útil, hora-pico da manhã do gerador

(4) Dia útil, hora-pico da tarde do gerador

\section{Avaliação da aplicabilidade do ITE 2012 para instituições brasileiras}

Após a análise das publicações do ITE, é importante avaliar se as taxas e modelos publicados na Edição 2012 refletem adequadamente a realidade brasileira. As Seções 3.1 e 3.2 apresentam essa avaliação no contexto das Instituições de Ensino Médio e Universidades, respectivamente.

\subsection{Avaliação para Instituições de Ensino Médio (IEMs)}

Um estudo comparativo foi desenvolvido para avaliar a capacidade de estimação das viagens por automóveis através das taxas do ITE (ITE, 2012) em situações observadas no Brasil. A Tabela 16 apresenta a comparação da estimação das taxas do ITE para os dados de viagens de 10 IEMs observados por Bertazzo (2008), para a cidade de Brasília, diferenciando cada instituição por seu caráter público (IEM PU) ou privado (IEM PR). 
Nas IEMs brasileiras foram pesquisados alunos e empregados para o turno da manhã, e não para todos os alunos matriculados no ensino médio. Essa segmentação é importante principalmente para as escolas públicas que oferecem até três turnos. O porte das IEMs brasileiras, pelo número de alunos, se posiciona dentro do intervalo de IEMs pesquisadas pelo ITE (200 a 2950 alunos), mas junto ao limite inferior. Quanto ao número de empregados, a IEM PU 03 tem número de empregados (39 empregados) inferior ao limite inferior do intervalo pesquisado pelo ITE (41 a 225 empregados).

Quanto à área construída, 7 das 10 escolas têm área construída inferior ao limite inferior do intervalo pesquisado pelo ITE (55 a 360 mil pés quadrados). Pelo porte das IEMs brasileiras e populações atendidas nos turnos de aula, observa-se que existem diferenças consideráveis entre a realidade brasileira e aquela pesquisada pelo ITE.

Além da análise de compatibilidade do porte das IEMs pesquisadas, outra comparação importante é verificar se as taxas do ITE conseguem estimar adequadamente a geração de viagens em IEMs no Brasil. Em seu manual (ITE, 2012), o ITE recomenda que não sejam usadas as taxas publicadas pelo ITE quando a variação das taxas locais e das do ITE for maior que $15 \%$. Nestes casos devem ser criadas novas taxas.

Pelos resultados apresentados na Tabela 17, a maioria dos períodos e variáveis estudadas teriam resultados superdimensionados se estimados pelas taxas do ITE, em relação à realidade observada. A exceção aparece em seis situações, apenas um caso em IEMs públicas e os demais para IEMs privadas. Conclui-se que a utilização das taxas do ITE para a realidade brasileira em IEMs implicaria em superdimensionamento da geração de viagens e da demanda por infraestruturas desnecessárias. 
Tabela 17 - Aplicação das Taxas do ITE (2012) em IEMs brasileiras

\begin{tabular}{|c|c|c|c|c|c|c|c|c|c|c|c|}
\hline & & & Dados IEMs & & & \multicolumn{6}{|c|}{ Períodos estudados } \\
\hline \multirow{3}{*}{$\begin{array}{l}\text { Instituição } \\
\text { de Ensino } \\
\text { Médio }\end{array}$} & \multirow{3}{*}{ Alunos } & \multirow{3}{*}{ Empregados } & \multirow{3}{*}{$\begin{array}{c}\text { Área bruta } \\
\text { construída em } \\
\mathrm{m}^{2}\end{array}$} & \multirow{3}{*}{$\begin{array}{c}\text { Área bruta } \\
\text { construída } \\
\text { em } \\
1000 \text { pés }^{2}\end{array}$} & & $\begin{array}{c}\text { Dia útil, pico } \\
\text { manhã }\end{array}$ & $\begin{array}{c}\text { Dia'útil pico } \\
\text { tarde do PGV }\end{array}$ & $\begin{array}{c}\text { Dia útil, pico } \\
\text { manhã }\end{array}$ & $\begin{array}{l}\text { Dia'útil pico } \\
\text { tarde do PGV }\end{array}$ & $\begin{array}{c}\text { Dia útil, pico } \\
\text { manhã }\end{array}$ & $\begin{array}{c}\text { Dia'útil pico } \\
\text { tarde do PGV }\end{array}$ \\
\hline & & & & & $\mathrm{X}$ & Estudantes & Estudantes & Empregados & Empregados & Área (1000pés²) & Área (1000pés ${ }^{2}$ \\
\hline & & & & & Tx ITE 2012 & 0,43 & 0,29 & 4,68 & 3,23 & 3,06 & 2,12 \\
\hline \multirow{3}{*}{ IEM PU 01} & \multirow{3}{*}{540} & \multirow{3}{*}{113} & \multirow{3}{*}{6250} & \multirow{3}{*}{67,2744} & Estimativa ITE & 232,2 & 156,6 & 528,84 & 364,99 & 205,86 & 142,62 \\
\hline & & & & & Observadas & 81 & 54 & 81 & 54 & 81 & 54 \\
\hline & & & & & \% variação & $65 \%$ & $66 \%$ & $85 \%$ & $85 \%$ & $61 \%$ & $62 \%$ \\
\hline \multirow{3}{*}{ IEM PU 02} & \multirow{3}{*}{296} & \multirow{3}{*}{56} & \multirow{3}{*}{3100} & \multirow{3}{*}{$33,3681^{* 1}$} & Estimativa ITE & 127,28 & 85,84 & 262,08 & 180,88 & 102,11 & 70,74 \\
\hline & & & & & Observadas & 28 & 21 & 28 & 21 & 28 & 21 \\
\hline & & & & & \% variação & $78 \%$ & $76 \%$ & $89 \%$ & $88 \%$ & $73 \%$ & $70 \%$ \\
\hline \multirow{3}{*}{ IEM PU 03} & \multirow{3}{*}{359} & \multirow{3}{*}{39} & \multirow{3}{*}{2280} & \multirow{3}{*}{$24,5417^{* 1}$} & Estimativa ITE & 154,37 & 104,11 & 182,52 & 125,97 & 75,10 & 52,03 \\
\hline & & & & & Observadas & 19 & 12 & 19 & 12 & 19 & 12 \\
\hline & & & & & $\%$ variação & $88 \%$ & $88 \%$ & $90 \%$ & $90 \%$ & $75 \%$ & $77 \%$ \\
\hline \multirow{3}{*}{ IEM PU 04} & \multirow{3}{*}{779} & \multirow{3}{*}{101} & \multirow{3}{*}{4879} & \multirow{3}{*}{$52,5171^{* 1}$} & Estimativa ITE & 334,97 & 225,91 & 472,68 & 326,23 & 160,70 & 111,34 \\
\hline & & & & & Observadas & 8 & 24 & 8 & 24 & 8 & 24 \\
\hline & & & & & $\%$ variação & $98 \%$ & $89 \%$ & $98 \%$ & $93 \%$ & $95 \%$ & $78 \%$ \\
\hline & & & & & Estimativa ITE & 234,35 & 158,05 & 463,32 & 319,77 & 101,55 & 70,35 \\
\hline IEM PU 05 & 545 & 99 & 3083 & $33,1851^{* 1}$ & Observadas & 105 & 15 & 105 & 15 & 105 & 15 \\
\hline & & & & & \% variação & $55 \%$ & $91 \%$ & $77 \%$ & $95 \%$ & $-3 \%$ & $79 \%$ \\
\hline & & & & & Estimativa ITE & 178,02 & 120,06 & 294,84 & 203,49 & 126,22 & 87,44 \\
\hline IEM PR 01 & 414 & 63 & 3832 & $41,2473^{* 1}$ & Observadas & 127 & 54 & 127 & 54 & 127 & 54 \\
\hline & & & & & \% variação & $29 \%$ & $55 \%$ & $57 \%$ & $73 \%$ & $-1 \%$ & $38 \%$ \\
\hline & & & & & Estimativa ITE & 116,96 & 78,88 & 500,76 & 345,61 & 85,84 & 59,47 \\
\hline IEM PR 02 & 272 & 107 & 2606 & $28,0507^{* 1}$ & Observadas & 136 & 62 & 136 & 62 & 136 & 62 \\
\hline & & & & & \% variação & $-16 \%$ & $21 \%$ & $73 \%$ & $82 \%$ & $-58 \%$ & $-4 \%$ \\
\hline & & & & & Estimativa ITE & 148,35 & 100,05 & 252,72 & 174,42 & 132,24 & 91,62 \\
\hline IEM PR 03 & 345 & 54 & 4015 & $43,2171^{* 1}$ & Observadas & 134 & 40 & 134 & 40 & 134 & 40 \\
\hline & & & & & \% variação & $10 \%$ & $60 \%$ & $47 \%$ & $77 \%$ & $-1 \%$ & $56 \%$ \\
\hline & & & & & Estimativa ITE & 120,4 & 81,2 & 631,8 & 436,05 & 395,25 & 273,83 \\
\hline IEM PR 04 & 280 & 135 & 12000 & 129,1669 & Observadas & 97 & 70 & 97 & 70 & 97 & 70 \\
\hline & & & & & \% variação & $19 \%$ & $14 \%$ & $85 \%$ & $84 \%$ & $75 \%$ & $74 \%$ \\
\hline & & & & & Estimativa ITE & 256,71 & 173,13 & 570,96 & 394,06 & 265,18 & 183,72 \\
\hline IEM PR 05 & 597 & 122 & 8051 & 86,6602 & Observadas & 119 & 82 & 119 & 82 & 119 & 82 \\
\hline & & & & & \% variação & $54 \%$ & $53 \%$ & $79 \%$ & $79 \%$ & $55 \%$ & $55 \%$ \\
\hline
\end{tabular}

Observações:*1 - Valores de área em pés quadrados menor que o mínimo do intervalo observado pelo ITE;*2 - Valor do número de empregados menor que o mínimo do intervalo observado pelo ITE;

Campos em cinza: Casos onde as taxas do ITE são aplicáveis (variação menor que 15\%);

No caso brasileiro: Todos os dados são referentes apenas ao turno da manhã; o pico da tarde do PGV é o horário de saída do turno da manhã, junto ao horário do almoço.

Conversão: $1 \mathrm{~m}^{2}=0,0107641000$ pés quadrados 


\subsection{Avaliação para Universidades}

Diferentes estudos têm sido realizados no Brasil com o objetivo de caracterizar as viagens realizadas de e para Universidades localizadas no país (Portugal et al., 2012). Nesses estudos é possível observar uma tendência crescente para estimar o número de viagens de pessoas e sua distribuição modal, ao invés de estimar somente o número de viagens por automóvel como previsto nas publicações do ITE.

A distribuição modal apresenta grande importância para o estudo das viagens geradas pelas universidades brasileiras, uma vez que os estudos realizados mostram percentagens destacadas de viagens realizadas a pé e por transporte público. Na maioria dos estudos é possível verificar, também, que as instituições incluídas na amostra são localizadas em áreas residenciais ou mistas, servidas por transporte público.

No que se refere a taxas e modelos, a influência dos trabalhos do ITE é acentuada. Destaca-se, entretanto, que os períodos de tempo analisados nos estudos brasileiros e as variáveis independentes adotadas são bastante limitados. Alguns estudos, por exemplo, estimam taxas para um dia típico, enquanto outros consideram a hora-pico de entrada e/ou saída dos turnos. A variável independente mais empregada é o número de estudantes.

Um estudo realizado na Universidade Federal de Santa Catarina - UFSC (Goldner et al., 2012), para o Campus da Trindade, localizado na cidade de Florianópolis, com 26500 estudantes, 1800 professores e 2800 empregados, obteve a seguinte distribuição modal: $56 \%$ de viagens realizadas em automóvel; $23 \%$ em transporte público; $17 \%$ a pé; e os $4 \%$ restantes por outros modos. O estudo estimou um total de 13790 viagens diárias de automóvel na chegada à instituição e um valor similar para as viagens na saída. Obteve, também, que nas duas horas-pico da manhã são realizadas em torno de $60 \%$ do total de viagens de entrada e nas duas horas-pico da tarde cerca de $45 \%$ das viagens de saída. Com base nesses dados é possível estimar taxas de geração diárias (entradas mais saídas) da ordem de 1 (uma) viagem de automóvel por estudante e 6 (seis) viagens de automóvel por empregado. Comparando essas taxas com as correspondentes na Edição 2012 do ITE, na ordem de 2 (duas) viagens por aluno e 9 (nove) viagens por empregado, verifica-se que as taxas obtidas para a UFSC são muito menores. Além 
disso, o fator horário de pico (FHP) obtido no referido estudo é, em princípio, superior em $8 \%$ ou $10 \%$ ao considerado pelo ITE.

Outro estudo realizado no Brasil, considerando 9 (nove) Instituições de Ensino Superior localizadas no Distrito Federal (Souza, 2007), obteve a distribuição modal das viagens e apresentou taxas e modelos de geração correspondentes. Para a distribuição modal, foi obtido que em torno de $52 \%$ das viagens foram realizadas em automóvel, $33 \%$ em transporte público, $7 \%$ a pé e $8 \%$ por outros modos. Os modelos de geração de viagens produzidos pelo estudo indicam que o número de automóveis atraídos em função das viagens de todos os usuários no início de um turno (hora-pico) pode ser estimado aplicando-se um fator de 0,676 sobre o número de alunos do turno. Para estimar o número correspondente de automóveis no final do turno, o fator a ser aplicado é de 0,639. A quantidade de viagens por dia depende da quantidade de turnos e o fator horário de pico (FHP) é elevado. Para um determinado turno, o total de viagens de automóveis (início mais final do turno) seria da ordem de 1,3 por aluno, com elevada concentração nos horários de pico.

Os estudos da TECTRAN $(2003,2004)$ tratam da distribuição modal, fator de ocupação média (passageiros/veículo) e apresentam modelos para estimar o número total de viagens atraídas pela instituição na hora pico (viagens de pessoas). A partir dos dados sobre a distribuição modal e taxa de ocupação média dos veículos (em torno de 1,4 pessoas por automóvel), as viagens veiculares podem então ser estimadas. Com relação à distribuição modal, os estudos obtiveram em torno de $40 \%$ para as viagens realizadas em automóvel, $46 \%$ em ônibus e vans e os $14 \%$ restantes a pé e por outros modos.

Outro estudo, realizado em quatro Universidades localizadas na cidade de Uberlândia (Paula, 2013) obteve taxas de atração e produção de viagens realizadas por alunos em cada um dos turnos das instituições, e as médias correspondentes. Foram obtidas a distribuição modal e as taxas para quatro modos de transporte: automóvel; ônibus e vans; motocicletas; e a pé e bicicleta. Com relação à distribuição modal, aproximadamente $30 \%$ do total das viagens foram realizadas em automóvel, $54 \%$ em ônibus e vans, $14 \%$ em motos e os $2 \%$ restantes a pé e em bicicleta. As taxas médias de atração e produção para automóveis foram de 0,325 e 0,362 viagens por aluno, respectivamente. Desta maneira, a taxa diária obtida (atração mais produção) foi da ordem de 0,7 viagens de automóveis por aluno. O fator horário de pico depende da 
quantidade de turnos existentes em cada instituição. Cabe destacar que neste estudo não foram consideradas as viagens realizadas por professores e funcionários.

Vale relatar ainda outro estudo realizado pela Universidade de São Paulo em São Carlos (Stein, 2013), que apresenta um extenso levantamento de informações para investigar barreiras, motivações e estratégias que representem potencial para a promoção da mobilidade sustentável. Empregando um questionário on line, se obteve uma taxa de resposta robusta e bem distribuída dos principais usuários do campus $(25,5 \%$ da população total). O campus I está localizado em área urbana consolidada, a 1600m distante do centro da cidade, e ainda servido por diversas vias arteriais e coletoras, sistema de transporte coletivo por ônibus e calçadas para pedestres. Para diferentes usuários do campus I, a distribuição modal varia significativamente. Para estudantes de graduação, aproximadamente $55 \%$ das viagens são realizadas a pé, e $30 \%$ por automóvel. Para estudantes de pós-graduação, 35\% realizam viagens ao campus a pé e $50 \%$ por automóvel. Já para servidores docentes, técnicos e administrativos, apenas $9 \%$ realizam viagens a pé e $85 \%$ utilizam o modo automóvel. Para todos os usuários a participação do modo ônibus observada é muito baixa (menor que 2\%). Para todos os alunos, foram observados mais usuários de bicicleta do que moto. No caso de servidores (técnicos administrativos e docentes) este caso se inverte.

Outros países da América Latina também têm desenvolvido estudos para a determinação da taxa de geração de viagens para Universidades, como é o caso do realizado em Córdoba, Argentina, que considerou 13 instituições (Herz et al., 2009). Esse estudo apresentou diferenças importantes com relação à distribuição modal e às taxas de geração correspondentes com base na localização da instituição (se está próxima ou distante do centro da cidade). Para as instituições próximas do centro da cidade, as viagens em automóvel representaram em torno de $24 \%$ do total de viagens, em ônibus $43 \%$, a pé $30 \%$ e em outros modos 3\%. Para as instituições afastadas do centro, a participação do automóvel passou para 53\%, a do ônibus para 45\%, não foram registradas viagens a pé e os outros modos responderam por $2 \%$ das viagens. As taxas diárias de viagens de automóvel foram da ordem de 0,30 por estudante para as instituições próximas do centro e da ordem de 0,65 viagens por aluno para as instituições localizadas na periferia. Com base em dados horários disponíveis para uma das instituições foi possível estimar uma fator horário de pico na ordem de $10 \%$ para as viagens veiculares por automóvel. 
A totalidade dos estudos revisados mostra a importância da distribuição modal, e que as viagens (de pessoas) por transporte público em vários casos superam as viagens realizadas em automóvel. Além disso, as taxas de geração de viagens de automóvel (viagens veiculares) apresentam variações importantes entre os estudos, mostrando-se bastante inferiores às reportadas pelo ITE, sendo que a distribuição horária dessas viagens apresenta maior concentração nos horários de pico do que o indicado pelo ITE.

\section{Conclusão}

O presente artigo revisou versões importantes da publicação Trip Generation do ITE no que diz respeito aos usos do solo 530 (Instituições de Ensino Médio) e 550 (Universidades). Para as Instituições de Ensino Médio (IEMs) a Edição 2012 reúne dados de 9 períodos diferentes de pesquisa e para 3 tipos de variáveis: "estudantes", "empregados" e "área construída" (em 1000 pés quadrados). Para os períodos mais significativos para as IEMs (em dia útil, hora pico do PGV pela manhã e à tarde), correspondentes aos períodos de entrada e saída de turno, esta edição reuniu mais de 70 estudos para a variável "estudantes". No caso das Universidades, as variáveis independentes consideradas são "estudantes" e "empregados". Para essas instituições o ITE apresenta, para as duas variáveis independentes, taxas para 6 (seis) períodos de tempo, que são: dia útil, sábado, hora-pico da manhã da via adjacente, hora-pico da tarde da via adjacente, hora-pico da manhã do gerador, e hora-pico da tarde do gerador. Exceto para o caso do sábado, o ITE apresenta também modelos de geração de viagens.

Nos estudos realizados no Brasil para as Universidades, as estimativas de taxas e modelos de geração de viagens são mais limitadas, tanto em termos de variáveis independentes consideradas quanto dos períodos de tempo analisados. Além disso, o número de estudos disponíveis ainda é pequeno. Porém, deve-se destacar que a Edição 2012 do ITE também considera um número reduzido de estudos para Universidades, atingindo um máximo de 10 estudos para alguns períodos analisados. Entre as Edições 2008 e 2012 foram agregados somente dois novos estudos, referentes a universidades com maior número de estudantes e localizadas em áreas servidas por transporte público. Em decorrência disso, as taxas de geração de viagens foram progressivamente sendo reduzidas para a variável independente "estudantes". 
O porte das IEMs consideradas pelo ITE, em número de alunos, é bem estável desde 1991, indicando que os novos estudos repetiram padrão de estudos já incluídos nos estudos anteriores. As taxas de geração de viagem se modificaram bastante entre as edições de 1991 e 2003, mas desde então sofreram pouca modificação. O ITE não diferenciou em seus estudos as IEMs pesquisadas pelo caráter público e privado, tampouco publicou informações sobre a utilização do transporte público nas edições mais recentes, limitando a comparação com o estudo brasileiro referenciado.

Como no Brasil as viagens geradas nas IEMs públicas têm forte dependência do modo ônibus (Bertazzo, 2008), esperava-se que a geração de viagens por automóveis nessas IEMs fosse inferior aos resultados estimados pelo ITE. De fato, na aplicação das taxas do ITE aos dados do estudo brasileiro, os dados de viagens foram superdimensionados para todos os períodos estudados em IEMs públicas, e em 26 dos 30 períodos estudados em IEMs privadas.

No que se refere às Universidades, os estudos realizados no Brasil e Argentina aqui revisados mostram que a distribuição modal das viagens pode variar de modo importante em função da disponibilidade de serviços de transporte público e da localização da instituição. Em termos gerais, é possível concluir que as taxas de geração de viagens de automóvel (viagens veiculares), em um dia útil típico, obtidas nesses estudos são inferiores às apresentadas na Edição 2012 do ITE. A Tabela 18 mostra a comparação entre alguns dos estudos revisados.

Tabela 18 - Comparação entre as taxas médias do ITE 2012 e de outros estudos

\begin{tabular}{l|c|c|c|c|c}
\hline Variável & Período & \multicolumn{4}{|c}{ Taxa Média } \\
\cline { 3 - 6 } Independente & de tempo & ITE, 2012 & Souza, 2007 & Paula, 2013 & $\begin{array}{c}\text { Herz et al., } \\
2009\end{array}$ \\
\hline Estudantes & Dia útil & 1,71 & 1,3 & $0,7 *$ & $0,2-0,65^{* *}$ \\
\hline *Somente para viagens de estudantes \\
** Para instituições localizadas no e fora do centro da cidade \\
\hline
\end{tabular}

Para os períodos relacionados aos horários de pico a comparação é mais complicada devido ao menor número de elementos disponíveis para a análise. A quantidade de turnos letivos oferecidos pela instituição influencia de modo destacado a concentração do pico das viagens. Em termos gerais, é possível considerar que as percentagens das viagens ocorridas na hora pico para as universidades brasileiras são superiores às propostas pelo ITE. 
Finalmente, cabe destacar que as taxas e modelos de geração de viagens de cada edição do Trip Generation são obtidos a partir da inclusão de novos estudos na base de dados. Se, por um lado, essa prática permite a determinação de taxas e modelos a partir de amostras cada vez maiores, por outro lado apresenta um sério inconveniente quanto à representação de novas práticas de gerenciamento da mobilidade que vêm sendo propostas e implementadas ao longo dos últimos anos, cuja ênfase tem sido a busca pela redução do número de viagens veiculares por automóvel. Apesar da Edição 2012 do manual explicitamente reconhecer que o impacto da disponibilidade de transporte público na área de localização do polo gerador é relevante, ela não deixa claro como esse impacto deve ser acomodado na aplicação das taxas e modelos de geração apresentados. No caso do Brasil, onde os estudos revelam que as viagens para instituições de ensino médio e universidades estão distribuídas, principalmente, entre os modos automóvel, transporte público e a pé, esta limitação compromete seriamente a qualidade das estimativas realizadas com o uso direto das taxas do ITE.

Assim, a partir das análises apresentadas no presente artigo, é possível concluir pela inadequação das taxas apresentadas na Edição 2012 do ITE para a estimativa de viagens veiculares geradas por instituições de ensino médio e universidades brasileiras. Cabe, também, recomendar o aprofundamento da pesquisa nacional visando à determinação das taxas de geração de viagens para os diferentes modos de transporte utilizados pelos usuários dessas instituições de ensino. 


\section{Referências}

Bertazzo, A. B. S. (2008) Estimativa e avaliação do padrão de viagens geradas para instituições de ensino médio. Dissertação (Mestrado em Transportes). Universidade de Brasília, Brasília.

Goldner, L. G., Beppler, F. e Prim, J. (2012) Análise da mobilidade em um campus universitário. In: PLURIS 2012 - Congresso Luso-brasileiro de Planejamento Urbano, Regional, Integrado e Sustentável, Brasília.

Herz, M., Galarraga J. e Pastor G. (2009) Características de generación y distribución modal de viajes en centros educativos universitarios. XV CLATPU Congreso Latinoamericano de Transporte Público y Urbano, Buenos Aires.

Institute of Transportation Engineers - ITE (1991) Trip generation. $5^{\text {a }}$ Edição. Washington, D.C.: ITE.

Institute of Transportation Engineers - ITE (2003) Trip generation. $7^{\mathrm{a}}$ Edição. Washington, D.C.: ITE.

Institute of Transportation Engineers - ITE (2008) Trip generation. $8^{\text {a }}$ Edição. Washington, D.C.: ITE.

Institute of Transportation Engineers - ITE (2012) Trip generation. 9a Edição. Washington, D.C.: ITE.

Jacques, M. A. P., Bertazzo, A. B. S., Galarraga, J. e Herz, M. (2010) Nova abordagem para o estudo das viagens geradas nas instituições de ensino. Transportes (Rio de Janeiro), vol. 18 , pp. 75-85.

Paula, A. F. F. C. (2013) Taxas de geração de viagens para instituições privadas de ensino superior de Uberlândia, MG. (Mestrado em Engenharia Civil), Universidade Federal de Uberlândia, Uberlândia .

Portugal, L. S. (Org.). (2012) Polos geradores de viagens orientados à qualidade de vida e ambiental. São Paulo: Editora Interciência.

Stein, P. P. (2013) Barreiras, Motivações e Estratégias para Mobilidade Sustentável no Campus São Carlos da USP. Dissertação (Mestrado em Engenharia de Transportes), Universidade de São Paulo, São Carlos.

Shoup, D. C. (2001) Truth in transportation planning. Transportation Research Board $80^{\text {th }}$ Annual Meeting, Washington, D.C.

Souza, S. C. F. (2007) Modelos para estimativa de viagens geradas por instituições de ensino superior. Dissertação (Mestrado em Transportes), Universidade de Brasília, Brasília DF.

Técnicos em Transporte Ltda - TECTRAN (2003) Estudo de circulação e estacionamento Unidade Arcos - PUC Minas. Belo Horizonte: TECTRAN.

Técnicos em Transporte Ltda - TECTRAN (2004) Relatório de impacto na circulação da Faculdade Estácio de Sá de Belo Horizonte - Campus Prado. Belo Horizonte TECTRAN. 